\title{
Management of the Neck in Squamous Cell Carcinoma of the Oral Cavity and Oropharynx: ASCO Clinical Practice Guideline
}

ASSOCIATED

CONTENT

Appendix

Data Supplement

Author affiliations and support information (if applicable) appear at the end of this article.

Accepted on November 14, 2018 and published at jco.org on February 27, 2019: DOI https:// doi.org/10.1200/JCO. 18.01921

Clinical Practice Guidelines

Committee approval: October 30, 2018

Editor's note: This American Society of Clinical Oncology (ASCO) Clinical

Practice Guideline provides recommendations, with comprehensive review and analyses of the relevant literature for each recommendation. Additional information, including a Data Supplement with additional evidence tables, a

Methodology Supplement, slide sets, clinical tools and resources, and links to patient information at www.cancer.net, is available at www.asco.org/ head-neck-cancerguidelines.

Reprint Requests: 2318 Mill Road, Suite 800, Alexandria, VA 22314; guidelines@ asco.org.

Shlomo A. Koyfman, MD ${ }^{1}$; Nofisat Ismaila, MD²; Doug Crook, MS ${ }^{3}$; Anil D'Cruz, DNB ${ }^{4}$; Cristina P. Rodriguez, MD ${ }^{5}$; David J. Sher, MD Damian Silbermins, MD; Erich M. Sturgis, MD ${ }^{8}$; Terance T. Tsue, MD ${ }^{9}$; Jared Weiss, MD ${ }^{10}$; Sue S. Yom, MD, PhD ${ }^{11}$; and F. Christopher Holsinger, MD ${ }^{12}$

PURPOSE The aim of the current work is to provide evidence-based recommendations to practicing physicians and others on the management of the neck in patients with squamous cell carcinoma of the oral cavity and oropharynx.

METHODS ASCO convened an Expert Panel of medical oncology, surgery, radiation oncology, and advocacy experts to conduct a literature search, which included systematic reviews, meta-analyses, randomized controlled trials, and prospective and retrospective comparative observational studies published from 1990 through 2018. Outcomes of interest included survival, regional disease control, neck recurrence, and quality of life. Expert Panel members used available evidence and informal consensus to develop evidence-based guideline recommendations.

RESULTS The literature search identified 124 relevant studies to inform the evidence base for this guideline. Six clinical scenarios were devised; three for oral cavity cancer and three for oropharynx cancer, and recommendations were generated for each one.

RECOMMENDATIONS For oral cavity cancers, clinical scenarios focused on the indications for and the hallmarks of a high-quality neck dissection, indications for postoperative radiotherapy or chemoradiotherapy, and whether radiotherapy alone is sufficient elective treatment of an undissected neck compared with high-quality neck dissection. For oropharynx cancers, clinical scenarios focused on hallmarks of a high-quality neck dissection, factors that would favor operative versus nonoperative primary management, and clarifying criteria for an incomplete response to definitive chemoradiation for which salvage neck dissection would be recommended. Consensus was reached and recommendations were made for all six clinical scenarios. Additional information is available at www.asco.org/head-neck-cancer-guidelines.

\section{J Clin Oncol 37:1753-1774. @ 2019 by American Society of Clinical Oncology}

\section{INTRODUCTION}

Head and neck cancer (HNC) remains a significant global public health problem, with more than 450,000 new diagnoses worldwide each year. ${ }^{1}$ For patients with $\mathrm{HNC}$, the presence of cervical lymph node metastases is associated with diminished overall survival. ${ }^{2}$ As squamous cell carcinoma of oral cavity (SCCOC) and oropharynx (SCCOP) comprise the majority of these cancers, ${ }^{1}$ and effective management of neck disease improves disease-specific and overall survival, ${ }^{3,4}$ these clinical practice guidelines were developed to clarify the guiding principles of managing the neck for these patients.

Although anatomically adjacent to each other, accumulating data suggest that, in many ways, SCCOC and SCCOP may be distinct diseases from a biologic perspective. Oral squamous cell carcinoma (SCC) is predominately associated with tobacco and betel nut use. $^{5}$ In contrast, SCCOP is increasing in incidence in recent decades as a result of chronic latent infections of the human papillomavirus (HPV) and seems to disproportionately affect younger people. ${ }^{6}$ The majority of patients with SCCOP have node-positive $(\mathrm{cN}+)$ necks at presentation, and $10 \%$ to $40 \%$ of patients without $\mathrm{cN}+$ necks at presentation will have occult nodal metastases in both SCCOC and SCCOP. ${ }^{7,8}$ As such, management of the neck is a critical component of high-quality oncologic care of these patients.

For decades, neck dissection and radiotherapy have served as the mainstays of treatment of cervical metastasis from both oral and oropharyngeal SCC. As our scientific understanding of the biology of these tumors has evolved and data have emerged that clarify the role of novel imaging, surgical, radiotherapeutic, and systemic therapies in these diseases, a need to articulate guiding principles in managing the neck in these diseases was identified. ${ }^{9-17}$ This guideline seeks to highlight relevant clinical questions about 
Management of the Neck in Squamous Cell Carcinoma of the Oral Cavity and Oropharynx: ASCO Clinical Practice Guideline

\section{Guideline Questions}

\section{Oral Cavity}

1. What are the indications for and the hallmarks of a high-quality neck dissection in oral cavity squamous cell carcinoma (SCCOC)?

2. Under what circumstances should a dissected neck receive adjuvant radiotherapy or chemoradiotherapy in patients with SCCOC?

3. Is neck radiotherapy to an undissected clinically node-negative (cNO) neck an adequate replacement for high-quality elective neck dissection in SCCOC?

\section{Oropharynx}

1. What are the hallmarks of a high-quality neck dissection in oropharynx squamous cell carcinoma (SCCOP)?

2. For patients with SCCOP, what features of clinical/radiographic nodal involvement would sway management away from surgery in favor of a nonoperative approach?

3. Under what circumstances should a patient with SCCOP undergo a neck dissection after definitive radiotherapy or chemoradiotherapy?

\section{Target Population}

Patients with SCCOC or SCCOP with nodal metastases or who are at risk for nodal metastases.

\section{Target Audience}

Medical oncologists, radiation oncologists, surgeons, nurses, speech pathologists, oncology pharmacists, and patients.

\section{Methods}

An Expert Panel was convened to develop clinical practice guideline recommendations on the basis of a systematic review of the medical literature.

\section{Recommendations}

\section{Oral Cavity}

Recommendation 1.1a. For patients with SCCOC classified as CT2 to CT4, cNO-that is, no clinical nor radiographic evidence of metastatic spread to the neck - and treated with curative-intent surgery, an ipsilateral elective neck dissection should be performed (Type: evidence based; Evidence quality: high, benefit outweighs harm; Strength of recommendation: strong).

Recommendation 1.1b. For patients with SCCOC classified as CT1, cNO, an ipsilateral elective neck dissection should be performed. Alternatively, for selected highly reliable patients with cT1, cNO, close surveillance may be offered by a surgeon in conjunction with specialized neck ultrasound surveillance techniques (Type: evidence based; Evidence quality: intermediate, benefit outweighs harm; Strength of recommendation: strong).

Recommendation 1.2a. For patients with a cNO neck, an ipsilateral elective neck dissection should include nodal levels, Ia, Ib, II, and III. An adequate dissection should include at least 18 lymph nodes (Type: evidence based; Evidence quality: high, benefit outweighs harm; Strength of recommendation: strong).

Recommendation 1.2b. An ipsilateral therapeutic selective neck dissection for a clinically node-positive (cN+) neck should include nodal levels la, Ib, Ila, IIb, III, and IV. An adequate dissection should include at least 18 lymph nodes. Dissection of level V may be offered in patients with multistation disease (Type: evidence based; Evidence quality: intermediate, benefit outweighs harm; Strength of recommendation: moderate).

Recommendation 1.3. In patients with a $\mathrm{cN}+$ contralateral neck, contralateral neck dissection should be performed. In patients with a cNO contralateral neck, an elective contralateral neck dissection may be offered in patients with a tumor of the oral tongue and/or floor of the mouth that is T3/4 or approaches midline (Type: evidence based; Evidence quality: intermediate, benefit outweighs harm; Strength of recommendation: moderate).

$$
\text { (continued on following page) }
$$




\section{THE BOTTOM LINE (CONTINUED)}

Recommendation 2.1a. Adjuvant neck radiotherapy should not be administered to patients with pathologically node-negative ( $\mathrm{pNO}$ ) or a single pathologically positive node ( $\mathrm{pN1}$ ) without extranodal extension after high-quality neck dissection, unless there are indications from the primary tumor characteristics, such as perineural invasion, lymphovascular space invasion, or a T3/4 primary (Type: evidence based; Evidence quality: intermediate, benefit outweighs harm; Strength of recommendation: moderate).

Recommendation 2.1b. Adjuvant neck radiotherapy should be administered to patients with oral cavity cancer and pN1 who did not undergo high-quality neck dissection - as defined in recommendation 1.2b (Type: evidence based; Evidence quality: intermediate, benefit outweighs harm; Strength of recommendation: moderate).

Recommendation 2.2. Adjuvant neck radiotherapy should be administered to patients with oral cavity cancer and pathologic N2 or N3 disease (Type: evidence based; Evidence quality: intermediate, benefit outweighs harm; Strength of recommendation: strong).

Recommendation 2.3a. Adjuvant chemoradiotherapy using intravenous bolus cisplatin $100 \mathrm{mg} / \mathrm{m}^{2}$ every 3 weeks should be offered to patients with oral cavity cancer and extranodal extension in any positive node, regardless of the extent of extranodal extension and the number or size of involved nodes, and no contraindications to high-dose cisplatin (Type: evidence based; Evidence quality: high, benefit outweighs harm; Strength of recommendation: strong).

Recommendation 2.3b. Concurrent weekly cisplatin may be administered with postoperative radiotherapy to patients who are considered inappropriate for standard high-dose intermittent cisplatin after a careful discussion of patient preferences and the limited evidence that supports this treatment schedule (Type: evidence based; Evidence quality: intermediate, benefit outweighs harm; Strength of recommendation: moderate).

Recommendation 3.1. Elective neck dissection is the preferred approach for patients with oral cavity cancer who require management of the clinically negative neck as outlined in recommendation 1.1a. Elective radiotherapy to a nondissected neck - 50 to 56 Gy in 25 to 30 fractions - may be efficacious and should be administered if surgery is not feasible (Type: evidence based; Evidence quality: intermediate, benefit outweighs harm; Strength of recommendation: moderate).

Recommendation 3.2. For patients who have undergone ipsilateral neck dissection only and are at substantial risk of contralateral nodal involvement-for example, tumor of the oral tongue and/or floor of the mouth that is T3/4 or approaches midline - contralateral neck radiotherapy should be administered to treat potential microscopic disease (Type: evidence based; Evidence quality: intermediate, benefit outweighs harm; Strength of recommendation: moderate).

\section{Oropharynx}

Recommendation 4.1. Patients with lateralized oropharyngeal carcinoma who are being treated with upfront curative surgery should undergo an ipsilateral neck dissection of levels II to IV. An adequate dissection should include at least 18 lymph nodes (Type: evidence based; Evidence quality: intermediate, benefit outweighs harm; Strength of recommendation: moderate).

Recommendation 4.2. Patients with lateralized oropharyngeal cancer who undergo neck dissection concurrently or before transoral endoscopic head and neck surgery should have ligation of at-risk feeding blood vessels to reduce the severity and incidence of postoperative bleeding (Type: evidence based; Evidence quality: low, benefit outweighs harm; Strength of recommendation: moderate).

Recommendation 4.3. Patients with tumors that extend to the midline tongue base or palate or that involve the posterior oropharyngeal wall should have bilateral neck dissections performed unless bilateral adjuvant radiotherapy is planned. The multidisciplinary team should discuss with patients the potential functional impact of bilateral neck dissection and postoperative adjuvant radiation therapy with or without chemotherapy (Type: evidence based; Evidence quality: intermediate, benefit outweighs harm; Strength of recommendation: moderate).

Recommendation 5.1. A nonsurgical approach should be offered to patients with $\mathrm{cN}+$ disease who have either unequivocal extranodal extension into surrounding soft tissues or carotid artery or cranial nerve involvement (Type: evidence based; Evidence quality: intermediate, benefit outweighs harm; Strength of recommendation: moderate).

Recommendation 5.2. Patients with biopsy-proven distant metastases should not undergo routine surgical resection of metastatic cervical lymph nodes (Type: evidence based; Evidence quality: intermediate, benefit outweighs harm; Strength of recommendation: strong).

\section{(continued on following page)}




\section{THE BOTTOM LINE (CONTINUED)}

Recommendation 6.1a. If positron emission tomography (PET)/computed tomography (CT) scan at 12 or more weeks after completion of radiation/chemoradiation shows intense fluorodeoxyglucose (FDG) uptake in any node, the patient should undergo neck dissection if feasible. If PET/CT shows no nodal FDG uptake and the patient has no abnormally enlarged lymph nodes, the patient should not have neck dissection (Type: evidence based; Evidence quality: high, benefit outweighs harm; Strength of recommendation: strong).

Recommendation 6.1b. Patients who complete radiation/chemoradiation and receive anatomic crosssectional imaging-CT or magnetic resonance imaging scans-at 12 or more weeks post-therapy that shows resolution of previously abnormal lymph nodes should not undergo neck dissection (Type: evidence based; Evidence quality: intermediate, benefit outweighs harm; Strength of recommendation: strong).

Recommendation 6.2. If PET/CT scan at 12 or more weeks shows mild FDG uptake in a node of $1 \mathrm{~cm}$ or less or a persistently enlarged node of $1 \mathrm{~cm}$ or more without either mild or intense FDG uptake, that patient may be observed closely with serial cross-sectional imaging or PET/CT, with neck dissection reserved for clinical or radiographic concern for progressive disease (Type: evidence based; Evidence quality: intermediate, benefit outweighs harm; Strength of recommendation: moderate).

ASCO believes that cancer clinical trials are vital to inform medical decisions and improve cancer care, and that all patients should have the opportunity to participate.

Additional Resources

More information, including a Data Supplement with additional evidence tables, a Methodology Supplement with information about evidence quality and strength of recommendations, slide sets, and clinical tools and resources, is available at www.asco.org/head-neck-cancer-guidelines. Patient information is available at www.cancer.net.

indications, quality measures, comparative efficacy of neck dissection and radiotherapy, and when and how to incorporate systemic therapy in these patients on the basis of nodal characteristics. This guideline harnesses the published data to provide evidence-based recommendations on these topics that are highly relevant to routine clinical practice.

\section{GUIDELINE QUESTIONS}

This clinical practice guideline addresses six overarching clinical questions that were grouped by anatomic location:

\section{Oral cavity:}

1. What are indications for and the hallmarks of a highquality neck dissection in SCCOC?

2. Under what circumstances should a dissected neck receive adjuvant radiotherapy or chemoradiotherapy in patients with SCCOC?

3. Is neck radiotherapy to an undissected clinically node negative ( $\mathrm{CNO}$ ) neck an adequate replacement for high-quality elective neck dissection in SCCOC?

Oropharynx:

1. What are the hallmarks of a high-quality neck dissection in SCCOP?

2. For patients with SCCOP, what features of clinical/ radiographic nodal involvement would sway management away from surgery in favor of a nonoperative approach?
3. Under what circumstances should a patient with SCCOP undergo neck dissection after definitive radiotherapy or chemoradiotherapy?

\section{METHODS}

\section{Guideline Development Process}

This systematic review-based guideline product was developed by a multidisciplinary Expert Panel, which included a patient representative and an ASCO guidelines staff member with health research methodology expertise (Appendix Table A1, online only). The Expert Panel also included representatives from the American Head and Neck Society and the American Society for Radiation Oncology in an effort to avoid duplication of guidelines on topics of mutual interest. The Expert Panel, cochaired by S.A.K. and F.C.H., met via teleconference and/or Webinar and corresponded through e-mail. On the basis of the consideration of the evidence, the authors were asked to contribute to the development of the guideline, provide critical review, and finalize the guideline recommendations. The guideline recommendations were sent for an open comment period of 2 weeks, allowing the public to review and comment on the recommendations after submitting a confidentiality agreement. These comments were taken into consideration while finalizing the recommendations. Members of the Expert Panel were responsible for reviewing and approving the penultimate version of guideline, which was then circulated for external review, and submitted to Journal of Clinical Oncology for editorial review 
and consideration for publication. All ASCO guidelines are ultimately reviewed and approved by the Expert Panel and the ASCO Clinical Practice Guidelines Committee before publication. All funding for the administration of the project was provided by ASCO.

The recommendations were developed by using a systematic review (1990-2018), which included systematic reviews, meta-analyses, randomized controlled trials, and prospective and retrospective comparative observational studies. Articles were selected for inclusion in the systematic review of the evidence on the basis of the following criteria:

- Population: patients with SCC metastatic to the neck from the oral cavity or oropharynx (staged N1 to N3), or patients with suspected or who are high-risk for occult SCC metastatic to the neck (staged NO; at-risk population).

- Interventions that focused on neck dissection, transoral endoscopic head and neck surgery (eHNS), sentinel lymph node (SLN) biopsy, radiation therapy, chemotherapy, and extracapsular extension-or extranodal extension or extracapsular extension.

- Study designs included were systematic reviews, meta-analyses, randomized controlled trials, and prospective and retrospective comparative observational studies.

Articles were excluded from systematic review if they were meeting abstracts not subsequently published in peerreviewed journals; editorials, commentaries, letters, news articles, case reports, or narrative reviews; or published in a non-English language.

Guideline recommendations are crafted, in part, using the Guidelines Into Decision Support methodology and accompanying BRIDGE-Wiz software. ${ }^{18}$ In addition, a guideline implementability review is conducted. On the basis of the implementability review, revisions were made to the draft to clarify recommended actions for clinical practice. Ratings for the type and strength of recommendation, evidence, and potential bias are provided with each recommendation (Methodology Supplement).

Detailed information about the methods used to develop this guideline is available in the Methodology Supplement at www.asco.org/head-neck-cancer-guidelines, including an overview (eg, panel composition, development process and revision dates); literature search and data extraction; the recommendation development process (Guidelines Into Decision Support and BRIDGE-Wiz); and quality assessment.

The ASCO Expert Panel and guidelines staff will work with cochairs to keep abreast of any substantive updates to the guideline. On the basis of formal review of the emerging literature, ASCO will determine the need to update. The update will be guided by the signals ${ }^{19}$ approach that is designed to identify only new, potentially practice-changing data-signals - that might translate into revised practice recommendations. The approach relies on targeted routine literature searching and the expertise of ASCO Expert Panel members to help identify potential signals. The Methodology Supplement (available at www.asco.org/head-neckcancer-guidelines) provides additional information about the signals approach. This is the most recent information as of the publication date.

\section{Guideline Disclaimer}

The Clinical Practice Guidelines and other guidance published herein are provided by the American Society of Clinical Oncology, Inc. (ASCO) to assist providers in clinical decision making. The information herein should not be relied upon as being complete or accurate, nor should it be considered as inclusive of all proper treatments or methods of care or as a statement of the standard of care. With the rapid development of scientific knowledge, new evidence may emerge between the time information is developed and when it is published or read. The information is not continually updated and may not reflect the most recent evidence. The information addresses only the topics specifically identified therein and is not applicable to other interventions, diseases, or stages of diseases. This information does not mandate any particular course of medical care. Further, the information is not intended to substitute for the independent professional judgment of the treating provider, as the information does not account for individual variation among patients. Recommendations reflect high, moderate, or low confidence that the recommendation reflects the net effect of a given course of action. The use of words like "must," "must not," "should," and "should not" indicates that a course of action is recommended or not recommended for either most or many patients, but there is latitude for the treating physician to select other courses of action in individual cases. In all cases, the selected course of action should be considered by the treating provider in the context of treating the individual patient. Use of the information is voluntary. ASCO provides this information on an "as is" basis and makes no warranty, express or implied, regarding the information. ASCO specifically disclaims any warranties of merchantability or fitness for a particular use or purpose. ASCO assumes no responsibility for any injury or damage to persons or property arising out of or related to any use of this information, or for any errors or omissions.

\section{Guideline and Conflicts of Interest}

The Expert Panel was assembled in accordance with ASCO's Conflict of Interest Policy Implementation for Clinical Practice Guidelines ("Policy," found at http://www. asco.org/rwc). All members of the Expert Panel completed ASCO's disclosure form, which requires disclosure of financial and other interests, including relationships with commercial entities that are reasonably likely to experience direct regulatory or commercial impact as a result of promulgation of the guideline. Categories for disclosure include 
TABLE 1. Types of Studies Identified in the Literature Search

CQ4

CQ5

CQ6

\begin{tabular}{|c|c|c|c|c|c|}
\hline Eight SR/MA $22,37,42-44,53,61,140$ & Two SR/MA 29,52 & One $\mathrm{RCT}^{30}$ & One SR/MA ${ }^{21}$ & One $\mathrm{SR} / \mathrm{MA}^{58}$ & Two RCTs ${ }^{45,46}$ \\
\hline Six RCTs $3,25,39,49,138,139$ & $\begin{array}{l}\text { Seven RCTs } \\
47,51,55\end{array}$ & $\begin{array}{l}\text { Two prospective } \\
\text { studies }^{26,27}\end{array}$ & $\begin{array}{l}\text { One prospective } \\
\text { study }^{28}\end{array}$ & Two RCTs 127,132 & $\begin{array}{l}\text { Six prospective } \\
\text { studies }^{48,54,130,134,141,142}\end{array}$ \\
\hline \multicolumn{4}{|l|}{$\begin{array}{l}\text { Twenty-three retrospective } \\
\text { studies } 62,73-78,80-83,87,88 \\
94,97,98,100,102,107,108,110,135,143\end{array}$} & \multicolumn{2}{|l|}{$\begin{array}{l}\text { Ten retrospective } \\
\text { studies }^{66,70,85,86,93,} \\
99,123-126\end{array}$} \\
\hline
\end{tabular}

Abbreviations: $\mathrm{CQ}$, clinical question $\mathrm{MA}$, meta-analysis; $\mathrm{RCT}$, randomized controlled trial; SR, systematic review.

employment; leadership; stock or other ownership; honoraria, consulting or advisory role; speaker's bureau; research funding; patents, royalties, other intellectual property; expert testimony; travel, accommodations, expenses; and other relationships. In accordance with the Policy, the majority of the members of the Expert Panel did not disclose any relationships constituting a conflict under the Policy.

\section{RESULTS}

A total of 124 studies met eligibility criteria and form the evidentiary basis for the guideline recommendations. ${ }^{3,20-143}$ Identified trials were published between 1990 and May 2018 and focused on neck dissection, SLN biopsy, radiation therapy, chemotherapy, and imaging studies. Primary outcomes reported in studies on surgical and therapeutic interventions included locoregional recurrence or control rate, overall survival, disease-free survival, and quality of life, whereas studies on imaging reported outcomes on diagnostic accuracy and negative and positive predictive value. Of note, whereas many of the studies quoted in this paper used the American Joint Committee on Cancer (AJCC) 7th edition, all references to stage in the recommendations in this guideline are based on the current 8th edition of the AJCC staging system. ${ }^{144}$ Table 1 provides a summary of the study designs of included studies. Details on the study characteristics are included in Data Supplement 1 . The systematic review flow diagram is shown in Figure 1.

\section{Study Quality Assessment}

Study design aspects related to individual study quality, strength of evidence, strength of recommendations, and risk of bias were assessed. Refer to the Methodology Supplement for more information and for definitions of ratings for overall potential risk of bias.

\section{RECOMMENDATIONS}

\section{Oral Cavity}

Clinical question 1. What are the indications for and the hallmarks of a high-quality neck dissection in SCCOC?
Recommendation 1.1a. For patients with SCCOC classified as cT2 to cT4, cNO-that is, no clinical nor radiographic evidence of metastatic spread to the neck-and treated with curative-intent surgery, an ipsilateral elective neck dissection should be performed (Type: evidence based; Evidence quality: high, benefit outweighs harm; Strength of recommendation: strong).

Recommendation 1.1b. For patients with SCCOC classified as cT1, cNO, an ipsilateral elective neck dissection should be performed. Alternatively, for selected highly reliable patients with cT1, cNO, close surveillance may be offered by a surgeon in conjunction with specialized neck ultrasound surveillance techniques (Type: evidence based; Evidence quality: intermediate, benefit outweighs harm; Strength of recommendation: strong).

Literature review and clinical interpretation. Ipsilateral elective neck dissection (END) is indicated in patients with locally advanced (T3 or T4) oral cavity cancer given the high risk-approximately $40 \%$ to $50 \%$-of microscopic nodal metastases in these patients. The benefit of END in patients with $\mathrm{T} 1$ to $\mathrm{T} 2$ oral cavity cancer has been more controversial. ${ }^{140} \mathrm{~A}$ number of prospective trials performed over two decades have yielded conflicting results. ${ }^{138,139,145,146}$ Whereas all trials found decreased incidence of regional recurrence in patients who were treated with an END, diseasefree and overall survival outcomes varied. Two trials with more extensive ENDs found no differences in disease-free and overall survival with addition of END. ${ }^{145,146}$ In the trial by Kligerman, ${ }^{140}$ in which elective surgery consisted of the more limited supraomohyoid neck dissection, disease-free survival was improved $(72 \% \vee 49 \% ; P=.04)$ at 3.5 years of follow-up in patients treated with END. A fairly recent systematic review found that there was insufficient evidence to support END in early-stage patients.

A recently published large, prospective, randomized clinical trial has shed light on this controversy. ${ }^{3}$ D'Cruz et al from the Tata Memorial Cancer Centre compared patients CT1 to cT2, cNO (AJCC 7th edition staging) who received END at the time of glossectomy (245 patients) with 255 


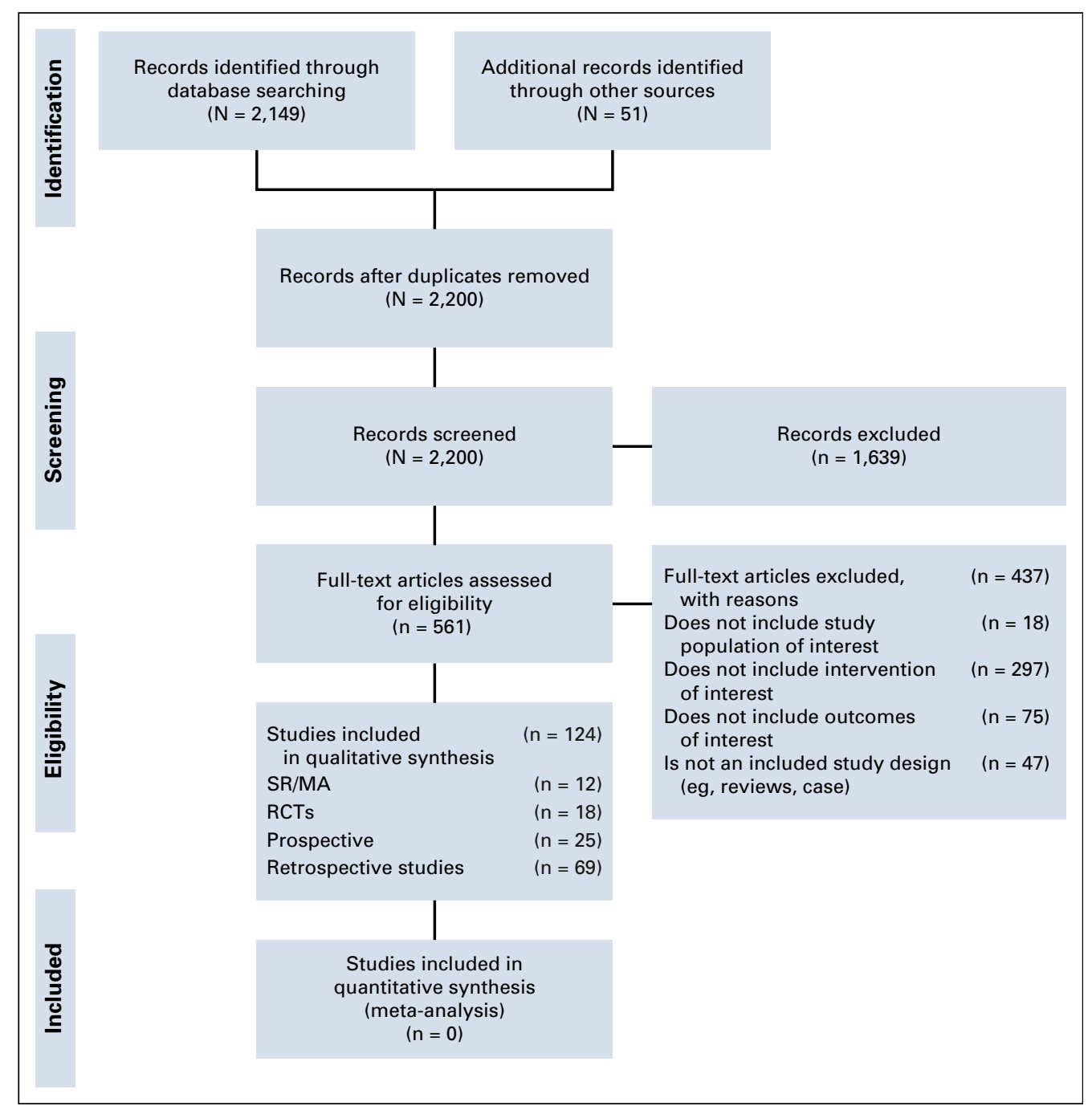

FIG 1. PRISMA 2009 flow diagram. MA, meta-analysis; SR, systematic review. patients who underwent therapeutic neck dissection only in the event of interval development of regional metastasis. At 3 years, patients who received upfront END had significantly improved overall survival $(80.0 \%$; $95 \% \mathrm{Cl}, 74.1 \%$ to $85.8 \%$ ) compared with those patients who had therapeuticonly dissection $(67.5 \%$; $95 \% \mathrm{Cl}, 61.0 \%$ to $73.9 \%$ ). Disease-specific survival was even more dramatically improved for patients who received END at $69.5 \%$ versus $45.9 \%$ for those patients who received therapeutic neck dissection. The key difference seemed to be explained by more advanced nodal stage and higher incidence of extracapsular spread in patients who did not undergo END at the time of glossectomy. In this study, incidence of nodal metastasis found at the time of END was $29.6 \%$. Critics of this approach ${ }^{147}$ have pointed out that $70 \%$ of patients received unnecessary surgery as there was no evidence of disease; however, the overall findings for the whole population suggest that routine END for cT1 to cT2 cNO improved overall survival.

Still, the debate continues in the literature regarding how this study should be implemented. Such alternatives as
SLN biopsy or watchful waiting have not been compared with END. Civantos et $a^{33}$ demonstrated in a prospective clinical trial of 140 patients that SLN biopsy correctly predicted a truly pathologically NO neck in $96 \%$ of cases. A European prospective observational study of SLN biopsy in 415 patients with $\mathrm{T} 1$ to T2NO oral cavity cancer showed a sensitivity of $86 \%$, a negative predictive value of $95 \%$, and a $94 \%$ disease-specific survival at 3 years of follow-up. ${ }^{148}$ The definitive follow-up study comparing SLN biopsy with END has not yet launched.

Another approach proposed by the Netherlands Cancer Institute Team involves a wait and watch strategy, ${ }^{149}$ which may still be appropriate for low-risk patients who agree and can commit faithfully to intensive frequent tumor surveillance with high-resolution and expert ultrasonography of the neck ${ }^{150}$; however, in certain practice settings, a patient's inability to participate in such a surveillance program and the absence of expertise in ultrasonography and accurate fine-needle aspiration biopsy technique may limit the efficacy of this approach. The Expert Panel acknowledges this important question and advocates for future 
prospective studies, perhaps to evaluate the role of END versus close observation or SLN biopsy. Future planned randomized studies of SLN biopsy versus END will help shed light on this question.

Recommendation 1.2a. For the patient with a cNO neck, an ipsilateral END should include nodal levels, la, Ib, II, and III. An adequate dissection should include at least 18 lymph nodes (Type: evidence based; Evidence quality: high, benefit outweighs harm; Strength of recommendation: strong).

Recommendation 1.2b. An ipsilateral therapeutic selective neck dissection for a $\mathrm{cN}+$ neck should include nodal levels la, Ib, Ila, IIb, III, and IV. An adequate dissection should include at least 18 lymph nodes. Dissection of level $\mathrm{V}$ may be offered in patients with multistation disease (Type: evidence based; Evidence quality: intermediate, benefit outweighs harm; Strength of recommendation: moderate).

Literature review and clinical interpretation. Ipsilateral END is performed for patients who are clinically and clinicoradiologically node negative. This procedure is usually prognostic (staging) and occasionally therapeutic for occult nodal metastasis. There have been two randomized studies to date ${ }^{39,131}$ to assess the extent and morbidity of supraomohyoid (levels I to III) versus modified neck dissection (levels | to V). Both studies showed the adequacy of supraomohyoid neck dissection, with more extensive dissection increasing morbidity (shoulder dysfunction) with no survival and recurrence benefit. In the largest prospective study on patterns of lymph node metastasis in 583 patients with oral nodal cancer, Pantvaidya et al ${ }^{106}$ found that there was no increased risk for an isolated skip metastasis to level IV in the absence of metastasis to the preceding levels.

In a randomized control trial, Guo et $\mathrm{al}^{39}$ has shown that the ipsilateral supraomohyoid neck dissection with resection of the clinically negative lymph node levels I to III is as surgically effective as a more extensive neck dissection. In their study, only $3.7 \%$ of clinically occult nodal metastases were pathologically detected in levels IV and V. In addition, more extensive dissection can result in increased postoperative shoulder function morbidity without a diseasespecific survival benefit, especially if dissection includes level IIb. ${ }^{39,49}$ Therefore, clearance of levels I to III is an adequate procedure for ipsilateral END for the clinically NO Neck.

In contrast, therapeutic neck dissection should include all clinically involved lymph node metastases $(\mathrm{cN}+)^{42,98,144}$ : nodes that are either palpably enlarged greater than $1 \mathrm{~cm}$ or radiographically enlarged greater than $1 \mathrm{~cm}$ in short axis and/or with central necrosis; or intense FDG avidity. Retrospective study of resected neck dissection specimens demonstrates that nodal involvement in level IV in the cN+ neck is not uncommon ${ }^{107,108}$ and should be included as part of the surgical treatment of the neck for resectable disease. Emphasis should be on the completeness of harvesting and pathologically analyzing all nodes at risk, as there is growing evidence in large national database and cohort studies of the importance of nodal yield reflecting the therapeutic effectiveness of neck dissection. ${ }^{76,77,102} \mathrm{~A}$ lymph node yield of 18 or more in neck dissections seems to have a survival advantage at 5 years in mucosally based head and neck carcinomas for patients with $\mathrm{cNO}$ and $\mathrm{cN}+$ disease. ${ }^{135,143,151}$ As such, pathologic analysis of the neck dissection specimen should be performed preferentially by pathologists with head and neck expertise to ensure optimal nodal yields are detected. ${ }^{152}$ Level $\mathrm{V}$ dissection poses a significant risk to the spinal accessory nerve and is not routinely included in a therapeutic neck dissection for oral cavity cancer. It may be offered in patients with multistation disease. $^{92,106,109}$

Recommendation 1.3. In patients with a $\mathrm{cN}+$ contralateral neck, a contralateral neck dissection should be performed. In patients with a cNO contralateral neck, an elective contralateral neck dissection may be offered in patients with a tumor of the oral tongue and/or floor of the mouth that is T3 or T4, or approaches midline (Type: evidence based; Evidence quality: intermediate, benefit outweighs harm; Strength of recommendation: moderate).

Literature review and clinical interpretation. As in recommendation 1.2, primary therapeutic neck dissection should notably include all clinically evident lymph node metastases, including those found contralaterally. Elective contralateral neck dissections can be considered in certain situations if the treatment plan includes an ipsilateral neck dissection. Retrospective studies have demonstrated certain factors that predispose a patient to occult contralateral nodal involvement. Large tumors (T3 or T4) have a high incidence of contralateral metastasis and warrant consideration for concurrent contralateral neck dissection. For tumors that approach the midline, contralateral neck dissection is usually considered, especially for those with a $\mathrm{cN}+$ ipsilateral neck. ${ }^{110}$ Increased tumor thickness in oral tongue cancers has been shown to have a high incidence of contralateral neck failures and may be combined with other factors to justify the utility of elective contralateral dissection. ${ }^{81}$ Finally, given the known lymphatic drainage patterns, floor of the mouth primaries have a predisposition for contralateral metastases, even at an earlier $\mathrm{T}$ stage.

Clinical question 2. Under what circumstances should a dissected neck receive adjuvant radiotherapy or chemoradiotherapy in patients with SCCOC?

Recommendation 2.1a. Adjuvant neck radiotherapy should not be administered to patients with pathologically nodenegative ( $\mathrm{pNO}$ ) or a single pathologically positive node (pN1) without extranodal extension after a high-quality neck dissection, unless there are indications from primary tumor characteristics, such as perineural invasion, lymphovascular space invasion, or a T3 or T4 primary (Type: evidence based; 
Evidence quality: intermediate, benefit outweighs harm; Strength of recommendation: moderate).

Recommendation 2.1b. Adjuvant neck radiotherapy should be administered to patients with oral cavity cancer and pN1 who did not undergo high-quality neck dissection-as defined in recommendation 1.2b (Type: evidence based; Evidence quality: intermediate, benefit outweighs harm; Strength of recommendation: moderate).

Literature review and clinical interpretation. The decision of whether to deliver neck postoperative radiotherapy (PORT) centers on the risk of microscopic disease that remains in the dissected field. There has only been one small randomized study of PORT in patients with oral cavity (buccal) cancer, which showed improved disease-free survival with PORT as a result of superior local control with no difference in neck recurrence. ${ }^{47}$ Thus, the expected regional recurrence risks after surveillance versus PORT are nearly entirely derived from retrospective studies. $\mathrm{Pa}$ tients with oral cavity cancer and no pathologically positive nodes generally have an excellent outcome from surgery alone, with regional recurrence risks in observed, pathologically negative necks nearly always less than 10\%, 29,67,91,111-115 which clearly supports observation if there are no indications for primary site radiotherapy.

Risk of recurrence after observation for patients with pN1 oral cavity carcinoma is more variable. Many retrospective series suggest a sufficiently low risk of isolated regional recurrenceless than $10 \%$-to pursue surveillance. ${ }^{112,114116}$ Conversely, other studies have shown a surprisingly high risk of in-field nodal recurrence and thus potential benefit for PORT in this population. ${ }^{68,104,113}$ One notable challenge in interpreting the literature is that the studies that have demonstrated a benefit included substantial numbers of patients who also had perineural invasion, lymphovascular invasion, or extranodal extension in whom adjuvant radiotherapy is well supported. Moreover, the N1 stage is heterogeneous, with a disease volume that ranges from a microscopic deposit to a 3-cm mass. Whereas the balance of the evidence base seems to suggest a low rate of recurrence in $\mathrm{pN} 1$ patients who do not have other high-risk primary tumor features, data here are somewhat limited and some head and neck oncologists feel strongly about adding adjuvant radiation for these patients. Thus, PORT should be administered to patients with pN1 disease who have an inadequate neck dissection. The Expert Panel acknowledges this controversy and suggests that teams consider prospective clinical trials to address this important clinical question.

Recommendation 2.2. Adjuvant neck radiotherapy should be administered to patients with oral cavity cancer and pathologic N2 or N3 disease (Type: evidence based; Evidence quality: intermediate, benefit outweighs harm; Strength of recommendation: strong).

Literature review and clinical interpretation. In contrast to data in low-volume neck disease, the literature consistently finds a high risk of regional or locoregional recurrence in patients with pathologic N2 or N3 neck presentation with or without radiotherapy. ${ }^{112,117,153}$ The single systematic review of this question also found a recurrence risk greater than $20 \%$ after surgery alone in three of five papers in node-positive disease. ${ }^{29}$ Retrospective studies that have assessed more broadly the relative benefit of PORT have clearly shown improvement in several outcomes with adjuvant radiotherapy ${ }^{90,104}$ in this higher-risk population. Regardless of nodal stage, the presence of extranodal extension was routinely found to increase the risk of regional recurrence and is a clear indication for PORT. ${ }^{68,153,154}$

Recommendation 2.3a. Adjuvant chemoradiotherapy using intravenous bolus cisplatin $100 \mathrm{mg} / \mathrm{m}^{2}$ every 3 weeks should be offered to patients with oral cavity cancer and extranodal extension in any positive node, regardless of the extent of extranodal extension and the number or size of involved nodes, and no contraindications to high-dose cisplatin (Type: evidence based; Evidence quality: high, benefit outweighs harm; Strength of recommendation: strong).

Recommendation 2.3b. Concurrent weekly cisplatin may be administered with postoperative radiotherapy to patients who are considered inappropriate for standard high-dose intermittent cisplatin after careful discussion of patient preferences and the limited evidence supporting this treatment schedule (Type: evidence based; Evidence quality: intermediate, benefit outweighs harm; Strength of recommendation: moderate).

Literature review and clinical interpretation. Addition of concurrent bolus cisplatin $100 \mathrm{mg} / \mathrm{m}^{2}$ every 3 weeks was investigated in two landmark randomized controlled trials, RTOG $9501^{35}$ and EORTC $22931 .{ }^{24}$ Although the eligibility criteria of the two studies were somewhat different, both trials included patients with extracapsular extension. In the only publication of the EORTC results, addition of bolus cisplatin improved locoregional control, progression-free survival, and overall survival. The contemporaneous report from RTOG 9501 demonstrated a comparable improvement in locoregional control and disease-free survival with concurrent bolus cisplatin, but no difference in overall survival. A subsequent combined analysis of these two studies showed the survival advantage was restricted to high-risk patients with either positive margins or extracapsular extension. ${ }^{123}$ Final results from RTOG 9501 continued to confirm a locoregional control and disease-free survival benefit with bolus cisplatin in this high-risk cohort, but an overall survival gain never materialized with longer follow-up.

There is a paucity of prospective evidence to support the use of concurrent weekly cisplatin in the postoperative setting. Bachaud ${ }^{136}$ reported on a small $(n=83)$, prospective, randomized study of weekly cisplatin-50 mg per week, approximately $30 \mathrm{mg} / \mathrm{m}^{2}$ - with postoperative radiotherapy 
explicitly for patients with extracapsular spread of disease. The authors found that the addition of cisplatin improved survival without locoregional recurrence, disease-free survival, and overall survival.

Noronha and colleagues ${ }^{132}$ recently published a phase III trial that randomly assigned patients who received definitive radiotherapy or PORT to concurrent bolus cisplatin or weekly cisplatin $30 \mathrm{mg} / \mathrm{m}^{2}$. The vast majority of patients were postoperative (93\%) with an oral cavity tumor (91\%), and more than $90 \%$ of patients had extracapsular extension. Results of the study were clear. Whereas bolus cisplatin was associated with more high-grade toxicity, it led to a statistically significant and clinically meaningful improvement in locoregional control (15\%). Therefore, bolus cisplatin remains the evidence-driven choice for concurrent chemotherapy in patients with extracapsular extension and platinum eligibility. Relative and absolute contraindication to bolus cisplatin in clinical practice is common, but alternative regimens have little evidence-based support.

The Expert Panel agrees with the recently published ASCO endorsement of the American Society for Radiation Oncology evidence-based clinical practice guideline on radiotherapy for oropharynx cancer that states, "concurrent weekly cisplatin may be delivered with postoperative radiotherapy to patients who are considered inappropriate for standard high-dose intermittent cisplatin after a careful discussion of patient preferences and the limited evidence supporting this treatment schedule."155,156(p4080) Of note, several clinical trials of postoperative chemoradiotherapy are using weekly cisplatin-based regimens-for example, RTOG 1216 and NRG HN-003. When available, the Expert Panel strongly endorses enrollment in clinical trials addressing novel nonplatinum-based regimens for patients with disease-based cisplatin indication, but comorbidity leading to cisplatin contraindication.

Clinical question 3. Is neck radiotherapy to an undissected cNO neck an adequate replacement for high-quality END in SCCOC?

Recommendation 3.1. END is the preferred approach for patients with oral cavity cancer who require management of the cNO neck as outlined in recommendation 1.1a. Elective radiotherapy to a nondissected neck-50 to 56 Gy in 25 to 30 fractions-may be efficacious and should be administered if surgery is not feasible (Type: evidence based; Evidence quality: intermediate, benefit outweighs harm; Strength of recommendation: moderate).

Literature review and clinical interpretation. There is a paucity of prospective evidence to address this question. Two small randomized trials were performed to investigate the efficacy of neck irradiation alone compared with surgery in combination with radiotherapy. ${ }^{30,55}$ Both trials closed early as a result of inferior outcomes in the nonoperative arms. Robertson et al ${ }^{55}$ reported on only 35 patients, one half of whom had radiation alone, one half of whom had surgery followed by postoperative radiation. In the radiation alone arm, 2-year survival was 10\% compared with 55\% in the surgery plus radiotherapy arm, which was likely driven by the $56 \%$ residual disease rate in the radiation alone arm. However, the primary mode of failure was in the originally $\mathrm{cN}+$ sites of disease, not the cNO sites, of the electively radiated neck. Carinci et $\mathrm{a}^{30}$ also published a small randomized trial comparing chemoradiation alone with surgery followed by postoperative radiation or chemoradiation. Overall, 2-year (52\% v 29\%) and 5-year (29\% v 0\%) disease-free survival data favored the surgical arm; however, there is no mention of whether the failure was in the originally cN+ sites or the electively treated neck. Similarly, there were only six patients with oral cavity cancer in that trial, making these studies minimally informative to this clinical question.

A small nonrandomized prospective study of patients with resected primary oral cavity cancers that warranted primary tumor bed radiation were treated with elective neck radiation in the absence of neck dissection. ${ }^{27}$ After 18 patients were treated in this fashion, six experienced a recurrence and the trial was closed, raising concern that radiation alone was insufficient. However, only four patients experienced failure in the neck as first failure and only two of these were in the radiation volumes, which yielded a crude rate of isolated failure in the electively radiated neck of approximately $11 \% .{ }^{27} \quad \mathrm{~A}$ second prospective nonrandomized study of elective neck irradiation in oral cavity cancer was performed in 221 patients who were treated with more than 50 Gy and showed a 7\% regional recurrence rate..$^{26}$ An additional caveat to these older studies is that they lacked the use of modern enhanced imaging techniques, such as positron emission tomography (PET)/ computed tomography (CT) or magnetic resonance imaging (MRI), and may have included patients with unrecognized gross nodal disease for which elective neck radiotherapy would have been inadequate.

A large retrospective study of 785 patients with head and neck cancer, one half of whom had oral cavity cancer examined outcomes of patients who were treated with elective neck radiotherapy. Some patients had pNO after negative neck dissections and most had no neck dissection and were cNO. Overall recurrence neck rates in patients who were radiated only compared with those who underwent neck dissection and adjuvant radiotherapy were similar (94\% v 97\%). On multivariable analysis, lack of neck dissection was associated with an increased risk of neck recurrence (hazard ratio, 4.8; $P=.003$ ), arguing for a benefit of neck dissection rather than radiotherapy alone. ${ }^{137}$ Conversely, there are several retrospective studies that have investigated the use of definitive (chemo)radiation in locally advanced oral cavity cancer. ${ }^{107-109}$ Whereas the primary goal of these studies was to establish the efficacy of radiation at eradicating gross disease, rates of failure in the 
elective nodal areas treated only with elective nodal radiation are promising. A recently published report on a $20-$ year experience of this approach demonstrated $79 \%$ locoregional control overall, with the majority of these treatment failures occurring in high-dose regions. ${ }^{118} \mathrm{Sim}$ ilarly, Scher et al ${ }^{119}$ demonstrated a 5\% rate of isolated regional failure and less than $10 \%$ overall rates of regional failure, many of which were in the high-dose gross tumor nonelective region. Finally, a large Indian retrospective study included 100 patients who were treated definitively with radiotherapy for oral cavity cancer. The study reported an isolated nodal failure rate of $7 \%$ with an additional $16 \%$ nodal failure rate in the presence of local failure. ${ }^{120}$ As such, the in-field regional recurrence rate in elective neck radiotherapy is quite low in several nonoperative studies, arguing that at least in the presence of chemotherapy, radiation can effectively sterilize micrometastatic neck disease.

Recommendation 3.2. For patients who have undergone ipsilateral neck dissection only and who are at substantial risk of contralateral nodal involvement-for example, tumor of the oral tongue and/or floor of the mouth that is T3 or T4 or approaches midline-contralateral neck radiotherapy should be administered to treat potential microscopic disease (Type: evidence based; Evidence quality: intermediate, benefit outweighs harm; Strength of recommendation: moderate).

Literature review and clinical interpretation. Principles of elective radiotherapy derive from the risk of clinically occult lymph node involvement in a particular clinical context. Principles of delivering elective neck radiation mirror the indications for a contralateral neck dissection in oral cavity cancer. As such, the evidence base referred to above in recommendation 1.3 supports the need for elective radiation of the contralateral cNO neck if a contralateral neck dissection is not performed.

\section{Oropharynx}

Clinical question 4. What are the hallmarks of a highquality neck dissection in SCCOP?

Recommendation 4.1. Patients with lateralized oropharyngeal carcinoma who are being treated with upfront curative surgery should undergo an ipsilateral neck dissection of levels II to IV. An adequate dissection should include at least 18 lymph nodes (Type: evidence based; Evidence quality: intermediate, benefit outweighs harm; Strength of recommendation: moderate).

Literature review and clinical interpretation. With the increasing incidence of HPV-related oropharyngeal carcinoma, ${ }^{157}$ the role of transoral endoscopic head and neck surgery performed via transoral laser microsurgery (TLM) or transoral robotic surgery (TORS) ${ }^{158}$ has greatly expanded within the multidisciplinary treatment paradigm. In one National Cancer Database study, primary surgical treatment of patients with T1 and T2 SCCOP increased from $56 \%$ of patients in 2004 to $82 \%$ in $2013(P<.001) .{ }^{159}$ Patients undergoing surgery as the definitive treatment modality should receive neck dissection. In a meta-analysis of clinical studies, ${ }^{65}$ patients who received END had an estimated 5year disease-specific survival rate of $97 \%$ versus $81 \%$ in patients who were observed (hazard ratio, 2.22).

The extent of neck dissection should include levels II, III, and IV. ${ }^{92,105}$ In a multi-institutional retrospective review, ${ }^{105}$ 324 patients underwent transoral eHNS and neck dissection, including levels II to IV and with and without levels I or V. In a study of 212 patients undergoing neck dissection, levels II to IV were the mostly commonly involved nodal echelons. $^{79}$

Some debate regarding the extent of the neck dissection continues. In particular, questions remain regarding whether to include level Ib. On the basis of American Academy of Otolaryngology-Head and Neck Surgery and American Head and Neck Society guidelines, ${ }^{160}$ level Ib involves all lymph nodes between the posterior edge of the submandibular gland, anterior belly of the digastric and the stylohyoid muscle, and includes pre- and postvascular nodes along the facial artery at the body of the mandible and glandular nodes associated with the submandibular gland. Whereas some authors ${ }^{101,161}$ advocated for routine dissection of level $\mathrm{lb}$, controversy remains about the oncologic value of dissecting the entirety of level Ib. However, a consensus that wide resection around level lla, including parts of $\mathrm{Ib}$ and $\mathrm{IIb}$ for $\mathrm{N}+$, seems to be clinically indicated does seem to exist. More controversial, though, is the role of bilateral neck dissection for primary oropharyngeal cancer and is discussed further in recommendation 4.3.

An adequate ipsilateral neck dissection should include at least 18 lymph nodes.

Analysis of prospective data from two clinical trials, RTOG 9501 and RTOG 0234, demonstrated that for patients undergoing neck dissection, a count of more than 18 lymph nodes was associated with increased survival and decreased rates of locoregional recurrence. ${ }^{77}$ Whereas the lymph node count is now emerging as a measure of quality for multidisciplinary head and neck oncology programs, this metric is the result not only of the surgeon's diligence during neck dissection, but also a systematic approach on the part of the pathology team. As such, it is preferred that experienced head and neck pathologists assess resection specimens to ensure the accurate determination of nodal yields. ${ }^{162}$

Recommendation 4.2. Patients with lateralized oropharyngeal cancer who undergo neck dissection concurrently or before transoral endoscopic head and neck surgery should have ligation of at-risk feeding blood vessels to reduce the severity and incidence of postoperative bleeding (Type: evidence based; Evidence quality: low, benefit outweighs harm; Strength of recommendation: moderate). 
Literature review and clinical interpretation. Postoperative hemorrhage is a potentially life-threatening complication after transoral eHNS, using TLM or TORS, ranging from $6.5 \%{ }^{121}$ to $13.2 \% .^{122}$ Two reports have highlighted the impact of elective ligation of the external carotid artery (ECA) during neck dissection. Whereas elective ligation of the ECA did not reduce the overall incidence of postoperative hemorrhage, severe bleeding complications were significantly reduced in patients with prophylactic ligation. The Expert Panel recommends that surgeons performing TORS or TLM with neck dissection routinely ligate at-risk branches of the ECA. However, there are currently no consensus guidelines about precise technique and/or the extent of ligation. The goal is to reduce the chance for bleeding from anterior branches of the ECA while minimizing the chance for injury to the internal carotid artery. Most experts recommend ligation with two 2-0 silk ties without division of the ECA. Some surgeons ligate the main trunk of the ECA at or above the takeoff of the superior thyroid artery. ${ }^{121}$ Some surgeons have advocated selective ligation on the basis of the location of the tumor-ligation of the facial artery for tumors of the tonsillar fossa, ligation of the lingual artery for tumors of the tongue base, and both for tumors of the glossopharyngeal sulcus. Future study will be required to refine technique and may come from the analysis of prospective data being collected as part of the ECOG3311 study. ${ }^{158}$

Recommendation 4.3. Patients with tumors that extend to the midline tongue base or palate or that involve the posterior oropharyngeal wall should have bilateral neck dissections performed unless bilateral adjuvant radiotherapy is planned. The multidisciplinary team should discuss with patients the potential functional impact of bilateral neck dissection and postoperative adjuvant radiotherapy with or without chemotherapy (Type: evidence based; Evidence quality: intermediate, benefit outweighs harm; Strength of recommendation: moderate).

Literature review and clinical interpretation. Several reports have highlighted the risk of contralateral lymph node metastasis from oropharyngeal carcinoma. ${ }^{21,72,101}$ Incidence ranges from $2 \%$ to $24 \%$ and seems to be influenced by $\mathrm{T} 4$, midline tumors, and the AJCC 7th edition nodal stage of greater than N2a. However, additional analysis is limited by a paucity of data using the latest 8th edition of nodal classification by the AJCC, which, among other changes, newly incorporates assessment of HPV status. This is particularly relevant because HPV biology affects both predisposition to nodal spread and modulates its prognostic relevance.

Clinical question 5. For patients with SCCOP, what features of clinical/radiographic nodal involvement would sway management away from surgery in favor of a nonoperative approach?

Recommendation 5.1. A nonsurgical approach should be offered to patients with $\mathrm{cN}+$ disease who have either unequivocal extranodal extension into surrounding soft tissues or carotid artery or cranial nerve involvement (Type: evidence based; Evidence quality: intermediate, benefit outweighs harm; Strength of recommendation: moderate).

Literature review and clinical interpretation. As contemporary randomized data comparing upfront surgical with nonsurgical (radiation-based) management of the neck is not available, decision making in this regard should be a multidisciplinary effort that considers both oncologic and functional patient outcomes. Patients in whom nodal characteristics indicate high-risk pathologic features that require postoperative full-dose chemoradiation and trimodality therapy ${ }^{24,34,123}$ should be offered curative-intent nonsurgical therapy. Pathologic extracapsular extension is a well-established risk factor for recurrence in resected mucosal SCCs. Addition of postoperative concurrent bolus cisplatin $100 \mathrm{mg} / \mathrm{m}^{2}$ every 3 weeks was investigated in two landmark randomized controlled trials, RTOG $9501^{35}$ and EORTC $22931 .{ }^{24}$ A subsequent combined analysis of these two studies demonstrated that the survival advantage was restricted to high-risk patients, which includes those with extracapsular extension. ${ }^{123}$ Among the prognostically superior p16+ oropharynx cancer subset, extracapsular extension has been reported in large single-institutional series, specifically extensive extracapsular extension with soft tissue metastases, ${ }^{124,125}$ as well as in registry-based data $^{126}$ to still correlate with adverse outcomes. Prabhu et $a^{99}$ examined the ability of CT imaging to accurately detect extensive extracapsular extension in a large singleinstitutional cohort and found that CT imaging was more sensitive at detecting higher-grade pathologic extracapsular extension. Similarly, patients with radiographically evident extranodal disease extension into cranial nerves whose quality of life would be impaired as a result of surgical resection of the hypoglossal or accessory nerve should be considered for nonsurgical treatment.

Randomized data exist that support concurrent cisplatinbased chemoradiation in patients with unresectable disease. An Intergroup phase III trial compared cisplatinbased concurrent chemoradiation with radiation alone or split-course multiagent concurrent chemoradiation in patients with unresectable HNC. ${ }^{127}$ In this study, nodal disease that was fixed to the carotid artery, the mastoid, base of skill of cervical spine, was deemed unresectable. A survival advantage was observed in the arm that received cisplatin $100 \mathrm{mg} / \mathrm{m}^{2}$ every 21 days concurrent with radiation. Weekly cisplatin dosing with radiotherapy has been adopted in recently completed and ongoing clinical trials; however, this regimen lacks level I evidence and registry data, ${ }^{163}$ and a recently completed randomized trial ${ }^{132}$ suggests inferior outcomes with weekly cisplatin compared with the regimen of $100 \mathrm{mg} / \mathrm{m}^{2}$ every 3 weeks. In view of this, whereas acknowledging the current use of $40 \mathrm{mg} / \mathrm{m}^{2}$ per week administration, now under evaluation in several National Cancer Institute-funded clinical trials, the Expert Panel consensus supports the use of every 21 days 
cisplatin administration until more prospective data from ongoing clinical trials become available.

A more detailed treatment of induction therapy and details about definitive chemoradiotherapy can be found in the recently published ASCO endorsement of the American Society for Radiation Oncology evidence-based clinical practice guideline on radiotherapy for oropharynx cancer. ${ }^{155}$

Recommendation 5.2. Patients with biopsy-proven distant metastases should not undergo routine surgical resection of metastatic cervical lymph nodes (Type: evidence based; Evidence quality: intermediate, benefit outweighs harm; Strength of recommendation: strong).

Literature review and clinical interpretation. Patients who present with distant hematogenous metastasis at diagnosis have incurable disease and the goals of therapy are directed toward palliation of symptoms and survival prolongation. In general, systemic therapy is the preferred route to achieve these goals, and multiple active systemic agents exist in this disease. Extensive clinical investigation has resulted in landmark studies that have demonstrated survival advantage with the use of platinum-based combinations $^{164}$ and programmed death-1 axis inhibitors. ${ }^{165}$ Occasionally, neck dissection may be indicated for palliative intent-for instance, to manage bleeding or open fungating wounds.

Clinical question 6. Under what circumstances should a patient with SCCOP receive a neck dissection after definitive radiotherapy or chemoradiotherapy?

Recommendation 6.1a. If PET/CT scan at 12 weeks or later after completion of radiation/chemoradiation shows intense FDG uptake in any node, the patient should undergo a neck dissection if feasible. If PET/CT scan shows no nodal FDG uptake and the patient has no abnormally enlarged lymph nodes, the patient should not have neck dissection (Type: evidence based; Evidence quality: high, benefit outweighs harm; Strength of recommendation: strong).

Recommendation 6.1b. Patients who complete radiation/ chemoradiation and have anatomic cross-sectional imaging CT or MRI scan-at 12 weeks or more post-therapy that shows resolution of previously abnormal lymph nodes should not have neck dissection (Type: evidence based; Evidence quality: intermediate, benefit outweighs harm; Strength of recommendation: strong).

Literature review and clinical interpretation. Recommendations in this section pertain to SCCOP, as standard management for oral cavity cancers usually includes either elective or therapeutic neck dissection as part of the initial ablative surgery. In SCCOP, for which curative-intent radiotherapy or chemoradiation may be delivered in the absence of an initial ablative surgery, patients who presented with advanced-stage disease in the neck (N2 to N3) have historically been provided a consolidative neck dissection after completion of radiation or chemoradiation. This practice arose in the era when chemoradiation was first introduced into the definitive management of oropharyngeal cancer. The major rationale was the high rate of pathologically persistent neck disease identified at short-term dissection in patients with N2 to N3 disease as well as a high rate of neck failure among patients with equivocal response on postradiotherapy CT scan. Additional justifications for planned neck dissection included the increased complications and relatively poor salvage rates associated with neck dissection at an interval greater than 4 to 12 weeks since radiotherapy completion.

Nonetheless, despite overall improvements in regional control rates achieved with planned postradiotherapy neck dissection, it could not be conclusively demonstrated that this practice improved locoregional control or overall survival among patients who were continuing to demonstrate response to therapy, especially when cross-sectional or functional imaging and physical exam confirmed complete or ongoing response. ${ }^{95} \mathrm{~A}$ prospective study demonstrated no obvious difference in outcomes among groups of patients who were managed with varying extents of neck dissection or no neck dissection at all. ${ }^{54}$

Of most importance, widespread introduction of PET/CT scan in the early 2000s led to a large number of singleinstitution studies ${ }^{130,133,134}$ demonstrating a high negative predictive value - more than 95\% - and moderate positive predictive value that was superior to CT scan alone in assessing the postradiotherapy neck. ${ }^{31,71}$ In these studies, the interval at which PET/CT scan was performed was noted to be critical, with many observations that diagnostic accuracy improved substantially at a time point of at least 10 to 12 weeks since the end of radiotherapy. ${ }^{128,129}$ These findings led many to advocate for serial observation, even for patients with persistent residual disease on crosssectional imaging, in the absence of clear hypermetabolic uptake on an appropriately timed PET/CT scan. ${ }^{48,89}$ Whereas many find reassurance in the high negative predictive value of PET/CT scan as correlated with longterm outcomes, alternatively some have suggested that the most effective use of PET/CT scan might be among patients who are at substantial risk of disease progression, such as p16-negative histologic types. ${ }^{130}$

A landmark multi-institutional, prospective, randomized trial — known as PET-NECK — was designed to prove the noninferiority of surveillance on the basis of PET/CT scan performed at 12 weeks after completion of chemoradiotherapy versus a planned neck dissection in patients with HNC with stage N2 to N3 disease. In the observation arm, only patients who demonstrated an incomplete or equivocal response on PET/CT scan received a neck dissection within 4 weeks of the scan, whereas all patients in the surgery arm had a planned neck dissection either within 4 weeks before chemoradiotherapy or within 4 to 8 weeks after chemoradiotherapy. In this trial, 564 patients were randomly assigned, of whom $84 \%$ had oropharyngeal 
cancer, $75 \%$ of which tested positive for p16. At a median follow-up of 36 months, the primary end point of equivalent overall survival was attained, with rates of $84.9 \%$ in the surveillance group and $81.5 \%$ in the planned neck dissection group. ${ }^{46}$ Locoregional control rates at 2 years were $91.9 \%$ in the surveillance group and $91.4 \%$ in the planned dissection group. The rate of surgical complications among the 54 patients who had neck dissection from the surveillance group was $42 \%$-this rate was $38 \%$ among the 221 patients in the surgery group. The surveillance strategy produced a cost savings of $\$ 2,190$ per patient and an incremental net health benefit of 0.21 quality-adjusted life years during the modeled lifetime horizon.

Recommendation 6.2. If PET/CT scan at 12 weeks or later shows mild FDG uptake in a node $1 \mathrm{~cm}$ or less or a persistently enlarged node $1 \mathrm{~cm}$ or greater without either mild or intense FDG uptake, that patient may be observed closely with serial cross-sectional imaging or PET/CT scan. Neck dissection is reserved for clinical or radiographic concern for progressive disease (Type: evidence based; Evidence quality: intermediate, benefit outweighs harm; Strength of recommendation: moderate).
Literature review and clinical interpretation. Of note, in the PET-NECK study, a residual mass without FDG uptake or mild FDG uptake in a normal-sized node was considered an incomplete or equivocal response, and these patients underwent neck dissection. The most conservative approach to enlarged structural anatomy or persistent lowlevel FDG avidity would be surgical dissection, and practitioners should consider this course of action in situations that warrant greater clinical concern. However, it has been shown that patients with residual lymph nodes that show no FDG uptake eventually achieve high rates of long-term locoregional control. ${ }^{141,142}$ These structural abnormalities may continue to resolve with time and are candidates for continued close surveillance. Likewise, mild FDG uptakefor example, SUV less than 3-may be frequently attributed to post-treatment inflammatory effects that may resolve with continued surveillance.

Figures 2 and 3 provide a visual interpretation of these recommendations in the management algorithm.

\section{PATIENT AND CLINICIAN COMMUNICATION}

As the advancement of science continues, controversies around old and new practices continue to arise. Improving

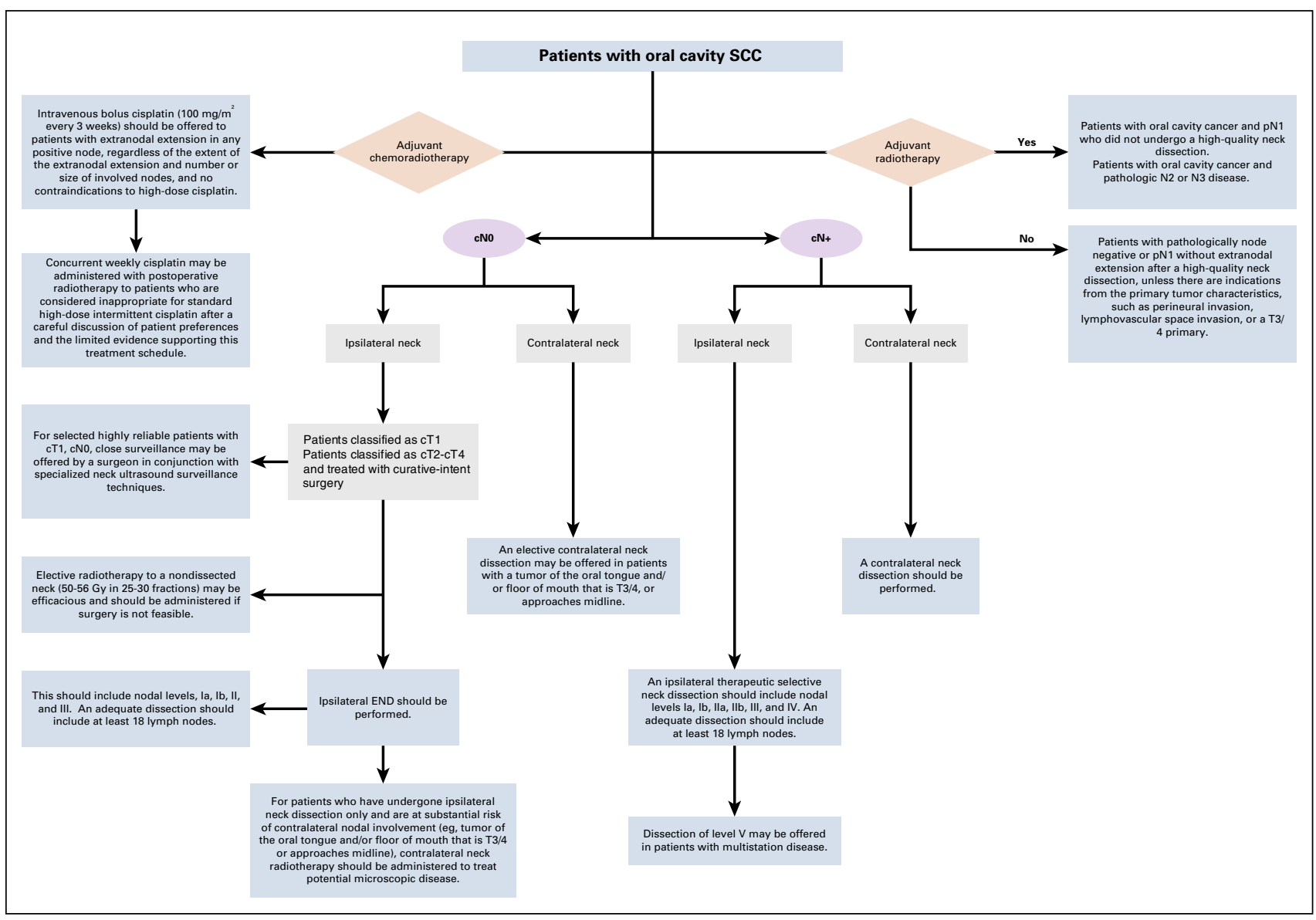

FIG 2. Treatment algorithm for management of the neck in patients with oral cavity squamous cell carcinoma (SCC) of the head and neck. cNO, clinically node negative; $\mathrm{cn}+$, clinically node positive; END, elective neck dissection; pN1, single pathologically node positive. 


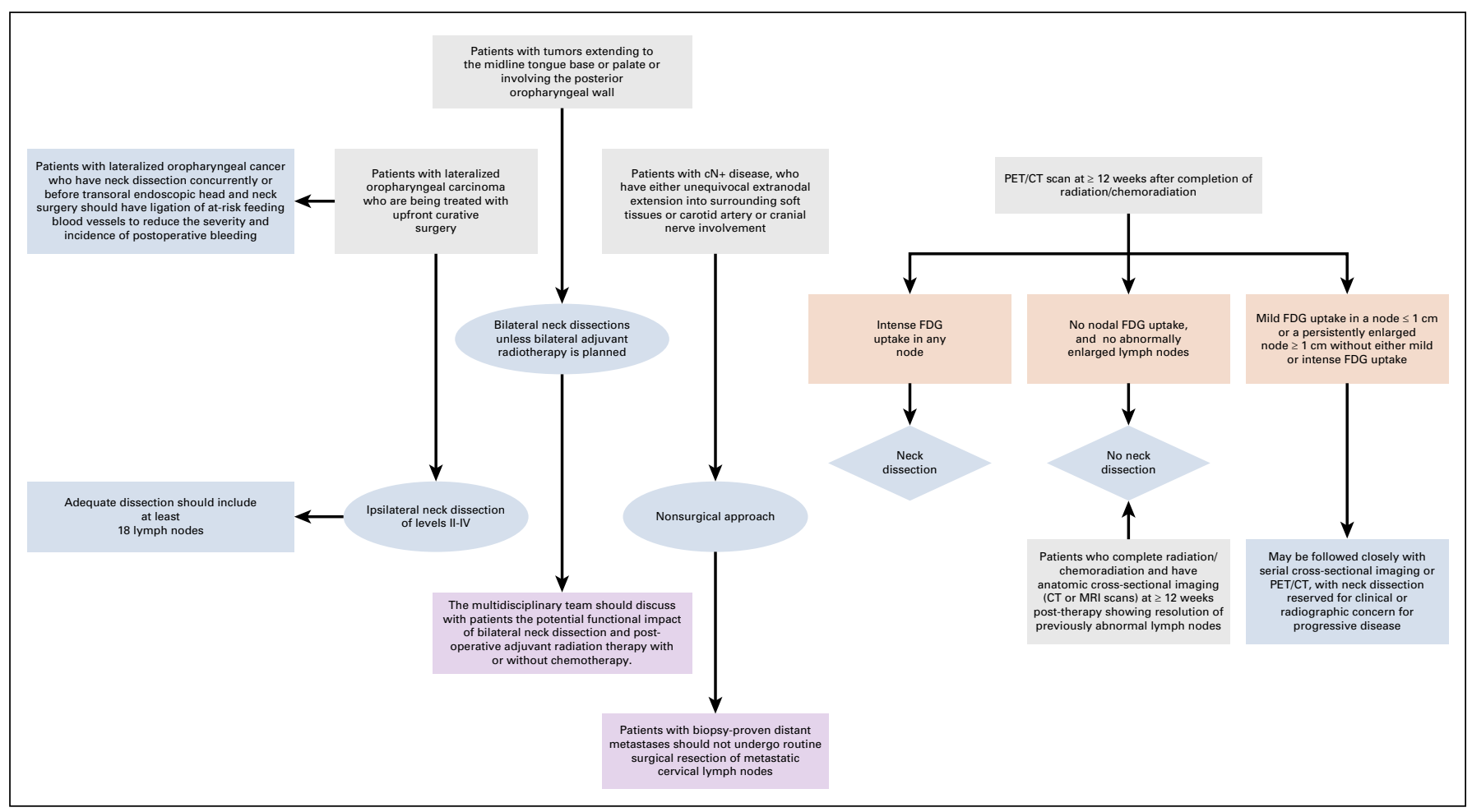

FIG 3. Treatment algorithm for management of the neck in patients with oropharyngeal squamous cell carcinoma of the head and neck. $\mathrm{cN}+$, clinically node positive; CT, computed tomography; FDG, fluorodeoxyglucose; MRI, magnetic resonance imaging; PET, positron emission tomography.

outcomes requires careful thoughtfulness in the continuous balance of the literature. The old aphorism stating that perfection is the enemy of the good would fit into any guideline.

Strategies to manage the neck in head in oral cavity and oropharynx cancers would naturally vary according to the experience of the head and neck multidisciplinary team and the availability of different technologies. As technology and our understanding of disease pathogenesis improve, patients are given even more options. That said, the head and neck oncologist faces a unique set of communication challenges given the daunting repercussions to a patient's quality of life as such areas as speech, taste, saliva, chewing, swallowing, lymphatic processes, nerve damage, teeth, facial bone structure, and physical appearance are affected.

This guideline does not seek to encompass all possible approaches, but in this day and age, given the dizzying pace of scientific complexities, some basics are clearer than others. A guiding principle is that an individualized discussion among the multidisciplinary team, the patient, and the patient's family is critical to optimal modern care. Given the involvement of multiple physicians and providers, many centers have developed navigators to facilitate processes and minimize the challenges patients face when they first come in contact with large systems. Identifying such resources as targeted support groups or other willing survivors could be instrumental in providing information and strategies tailored specifically to patients' treatment experience.
ASCO has long believed that strong and clear communication between physicians, patients, and families is paramount for the delivery of quality care.

For recommendations and strategies to optimize patientclinician communication, see "Patient-Clinician Communication: American Society of Clinical Oncology Consensus Guideline."166

\section{HEALTH DISPARITIES}

Although ASCO clinical practice guidelines represent expert recommendations on the best practices in disease management to provide the highest level of cancer care, it is important to note that many patients have limited access to medical care. Racial and ethnic disparities in health care contribute significantly to this problem in the United States. Patients with cancer who are members of racial and ethnic minorities suffer disproportionately from comorbidities, experience more substantial obstacles to receiving care, are more likely to be uninsured, and are at greater risk of receiving care of poor quality than other Americans. ${ }^{167-170}$

Many other patients lack access to care because of their geographic location and distance from appropriate treatment facilities. Financial toxicity is rapidly becoming a forefront topic in oncology conferences and clearly affects both access to care and quality of life.

Awareness of these disparities in access to care should be considered in the context of this clinical practice guideline, 
and health care providers should strive to deliver the highest level of cancer care to these vulnerable populations.

\section{MULTIPLE CHRONIC CONDITIONS}

Comorbidities and performance status are significant prognostic factors across any medical problem. Compounding factors, such as smoking, number of recent hospitalizations, or the availability of a caretaker, limit the widespread application of broad guidelines down to an individual.

Creating evidence-based recommendations to inform the treatment of patients with additional chronic conditions, a situation in which the patient may have two or more such conditions-referred to as multiple chronic conditions (MCCs) - is challenging. Patients with MCCs are a complex and heterogeneous population, making it difficult to account for all of the possible permutations so as to develop specific recommendations for care. In addition, the best available evidence for treating index conditions, such as cancer, is often from clinical trials, the study selection criteria of which may exclude these patients to avoid potential interaction effects or confounding of results associated with MCCs. As a result, the reliability of outcome data from these studies may be limited, thereby creating constraints for expert groups to make recommendations for care in this heterogeneous patient population.

As many patients for whom guideline recommendations apply present with MCCs, any treatment plan must account for the complexity and uncertainty created by the presence of MCCs and highlights the importance of shared decision making regarding guideline use and implementation. Therefore, in consideration of the recommended care for the target index condition, clinicians should review all other chronic conditions present in the patient and account for those conditions when formulating the treatment and follow-up plan.

In light of the above considerations, practice guidelines should provide information on how to apply the recommendations for patients with MCCs, perhaps as a qualifying statement for recommended care. This may mean that some or all of the recommended care options may be modified or not applied, as determined by best practice in consideration of any MCC.

\section{COST IMPLICATIONS}

Increasingly, individuals with cancer are required to pay a larger proportion of their treatment costs through deductibles and coinsurance. ${ }^{171,172}$ Higher patient out-ofpocket costs have been shown to be a barrier to initiating and adhering to recommended cancer treatments. ${ }^{173,174}$

Discussion of cost can be an important part of shared decision making. ${ }^{175}$ Clinicians should discuss with patients the use of less expensive alternatives when practical and feasible for the treatment of the patient's disease and when there are two or more treatment options that are comparable in terms of benefits and harms. ${ }^{175}$
Patient out-of-pocket costs may vary depending on insurance coverage. Coverage may originate in the medical or pharmacy benefit, which may have different cost-sharing arrangements. Patients should be aware that different products may be preferred or covered by their particular insurance plans. Even with the same insurance plan, the price may vary between different pharmacies. When discussing financial issues and concerns, patients should be made aware of any financial counseling services that are available to address this complex and heterogeneous landscape. ${ }^{175}$

As part of the guideline development process, ASCO may opt to search the literature for published cost effectiveness analyses that might inform the relative value of available treatment options. Excluded from consideration are cost effectiveness analyses that lack contemporary cost data and agents that are not currently available in either the United States or Canada and/or are industry sponsored. Whereas there have been some cost effectiveness analyses of transoral robotic surgery, advanced imaging technologies, and SLN biopsy in HNC, definitive conclusions cannot be drawn as a result of a paucity of data.

\section{EXTERNAL REVIEW AND OPEN COMMENT}

Draft recommendations were released to the public for open comment from May 21, 2018, through May 31, 2018. Response categories of "Agree as written," "Agree with suggested modifications," and "Disagree. See comments" were captured for every proposed recommendation with 31 written comments received. A total of $89.5 \%$ of responses were either agreed or agreed with slight modifications to the recommendations and 10.5\% of the responses were disagree. Expert Panel members reviewed comments from all sources and determined whether to maintain original draft recommendations, to revise with minor language changes, or to consider major recommendation revisions. All changes were incorporated before Clinical Practice Guidelines Committee review and approval.

\section{GUIDELINE IMPLEMENTATION}

ASCO guidelines are developed for implementation across health settings. Barriers to implementation include the need to increase awareness of the guideline recommendations among front-line practitioners and survivors of cancer and caregivers, as well as to provide adequate services in the face of limited resources. The guideline Bottom Line Box was designed to facilitate implementation of recommendations. This guideline will be distributed widely through the ASCO Practice Guideline Implementation Network. ASCO guidelines are posted on the ASCO Web site and most often published in Journal of Clinical Oncology and Journal of Oncology Practice. 


\section{LIMITATION OF THE RESEARCH AND FUTURE RESEARCH}

These recommendations are largely limited by a paucity of high-quality level I evidence to guide clinical decision making in managing the neck in patients with oral cavity and oropharyngeal cancers. This is a result, in part, of decades of retrospective historical data and empirical experience having established patterns of practice that are well accepted and for which equipoise is absent, preventing prospective validation of entrenched standards of care. In addition, some of the clinical scenarios addressed in these guidelines are clinically meaningful but of a subtle nature that apply to subpopulations of patients for which prospective clinical trials are impractical. Another limitation of the data is that much of the robust retrospective bodies of data that inform these scenarios include HPV-associated and -unassociated patients in the same studies, or these studies were performed in the pre-HPV era, which makes it difficult to apply that data to modern circumstances. More sophisticated imaging modalities, such as MRI and PET/CT scan, have also radically changed our ability to radiographically detect nodal metastases, rendering much of the old data inapplicable to the modern patient. With these caveats, we believe we have chosen questions for which there is enough evidence to make compelling recommendations and, most importantly, to frame the questions about which future prospective trials can shed much light.

ASCO believes that cancer clinical trials are vital to inform medical decisions and improve cancer care, and that all patients should have the opportunity to participate.

\section{ADDITIONAL RESOURCES}

More information, including a Data Supplement with additional evidence tables, a Methodology Supplement with information about evidence quality and strength of recommendations, slide sets, and clinical tools and resources, is available at www.asco.org/head-neck-cancer-guidelines. Patient information is available at www.cancer.net.

\section{RELATED ASCO GUIDELINES}

- Integration of Palliative Care into Standard Oncology Practice ${ }^{176}$ (http://ascopubs.org/doi/10.1200/ JC0.2016.70.1474).

- Patient-Clinician Communication ${ }^{166}$ (http:// ascopubs.org/doi/10.1200/JC0.2017.75.2311).

- Human Papillomavirus Testing in Head and Neck Carcinomas ${ }^{177}$ (http://ascopubs.org/doi/ 10.1200/JC0.18.00684).

- Use of Larynx-Preservation Strategies in the Treatment of Laryngeal Cancer Update ${ }^{178}$ (http:// ascopubs.org/doi/10.1200/JC0.2017.75.7385).

- Radiation Therapy for Oropharyngeal Squamous Cell Carcinoma ${ }^{155}$ (http://ascopubs.org/doi/10.1200/ JC0.2017.73.8633).

- Head and Neck Cancer Survivorship Care ${ }^{179}$ (http://ascopubs.org/doi/10.1200/ JCO.2016.71.8478).

\section{AFFILIATIONS}

${ }^{1}$ Cleveland Clinic, Cleveland, $\mathrm{OH}$

${ }^{2}$ American Society of Clinical Oncology, Alexandria, VA

${ }^{3}$ Patient representative, Indianapolis, IN

${ }^{4}$ Tata Memorial Centre, Mumbai, India

${ }^{5}$ University of Washington, Seattle, WA

${ }^{6}$ University of Texas Southwestern, Dallas, TX

${ }^{7}$ Huntington Internal Medicine Group, Huntington, WV

${ }^{8}$ Anderson Cancer Center, Houston, TX

${ }^{9}$ University of Kansas Cancer Center, Kansas City, KS

${ }^{10}$ University of North Carolina, Chapel Hill, NC

${ }^{11}$ University of California, San Francisco, San Francisco, CA

${ }^{12}$ Stanford University, Palo Alto, CA

\section{CORRESPONDING AUTHOR}

American Society of Clinical Oncology, 2318 Mill Rd, Suite 800, Alexandria, VA 22314; e-mail: guidelines@asco.org.

\begin{abstract}
AUTHORS' DISCLOSURES OF POTENTIAL CONFLICTS OF INTEREST AND DATA AVAILABILITY STATEMENT

Disclosures provided by the authors and data availability statement (if applicable) are available with this article at DOI https://doi.org/10.1200/ JC0.18.01921

AUTHOR CONTRIBUTIONS

Manuscript writing: All authors

Final approval of manuscript: All authors

Accountable for all aspects of the work: All authors

\section{ACKNOWLEDGMENT}

The Expert Panel wishes to thank Harold Lau, MD, and Lalan Wilfong, MD, and the Clinical Practice Guidelines Committee for their thoughtful reviews and insightful comments on this guideline.
\end{abstract}

\section{EQUAL CONTRIBUTION}

S.A.K. and F.C.H. were Expert Panel co-chairs.

\section{REFERENCES}

1. Torre LA, Bray F, Siegel RL, et al: Global cancer statistics, 2012. CA Cancer J Clin 65:87-108, 2015

2. Schuller DE, McGuirt WF, McCabe BF, et al: The prognostic significance of metastatic cervical lymph nodes. Laryngoscope 90:557-570, 1980 
3. D'Cruz AK, Vaish R, Kapre N, et al: Elective versus therapeutic neck dissection in node-negative oral cancer. N Engl J Med 373:521-529, 2015

4. O'Sullivan B, Huang SH, Su J, et al: Development and validation of a staging system for HPV-related oropharyngeal cancer by the International Collaboration on Oropharyngeal cancer Network for Staging (ICON-S): A multicentre cohort study. Lancet Oncol 17:440-451, 2016

5. Sturgis EM, Cinciripini PM: Trends in head and neck cancer incidence in relation to smoking prevalence: An emerging epidemic of human papillomavirusassociated cancers? Cancer 110:1429-1435, 2007

6. Hussein AA, Helder MN, de Visscher JG, et al: Global incidence of oral and oropharynx cancer in patients younger than 45 years versus older patients: A systematic review. Eur J Cancer 82:115-127, 2017

7. Amini A, Jasem J, Jones BL, et al: Predictors of overall survival in human papillomavirus-associated oropharyngeal cancer using the National Cancer Data Base. Oral Oncol 56:1-7, 2016

8. Kuo P, Mehra S, Sosa JA, et al: Proposing prognostic thresholds for lymph node yield in clinically lymph node-negative and lymph node-positive cancers of the oral cavity. Cancer 122:3624-3631, 2016

9. Helsen N, Van den Wyngaert T, Carp L, et al: FDG-PET/CT for treatment response assessment in head and neck squamous cell carcinoma: A systematic review and meta-analysis of diagnostic performance. Eur J Nucl Med Mol Imaging 45:1063-1071, 2018

10. Ng SP, Johnson JM, Gunn GB, et al: Significance of negative post-treatment 18-FDG PET/CT imaging in patients with p16/HPV-positive oropharyngeal cancer. Int J Radiat Oncol Biol Phys 102:1029-1035, 2018

11. Brizel DM: Head and neck cancer as a model for advances in imaging prognosis, early assessment, and posttherapy evaluation. Cancer J 17:159-165, 2011

12. Ward MC, Koyfman SA: Transoral robotic surgery: The radiation oncologist's perspective. Oral Oncol 60:96-102, 2016

13. Hutcheson KA, Holsinger FC, Kupferman ME, et al: Functional outcomes after TORS for oropharyngeal cancer: A systematic review. Eur Arch Otorhinolaryngol 272:463-471, 2015

14. Lörincz BB, Jowett N, Knecht R: Decision management in transoral robotic surgery: Indications, individual patient selection, and role in the multidisciplinary treatment for head and neck cancer from a European perspective. Head Neck 38:E2190-E2196, 2016 (suppl 1)

15. Marta GN, Silva V, de Andrade Carvalho H, et al: Intensity-modulated radiation therapy for head and neck cancer: Systematic review and meta-analysis. Radiother Oncol 110:9-15, 2014

16. O'Sullivan B, Rumble RB, Warde P: Intensity-modulated radiotherapy in the treatment of head and neck cancer. Clin Oncol (R Coll Radiol) 24:474-487, 2012

17. Mendenhall NP, Malyapa RS, Su Z, et al: Proton therapy for head and neck cancer: Rationale, potential indications, practical considerations, and current clinical evidence. Acta Oncol 50:763-771, 2011

18. Shiffman RN, Michel G, Rosenfeld RM, et al: Building better guidelines with BRIDGE-Wiz: Development and evaluation of a software assistant to promote clarity, transparency, and implementability. J Am Med Inform Assoc 19:94-101, 2012

19. Shojania KG, Sampson M, Ansari MT, et al: How quickly do systematic reviews go out of date? A survival analysis. Ann Intern Med 147:224-233, 2007

20. Adel M, Kao HK, Hsu CL, et al: Evaluation of lymphatic and vascular invasion in relation to clinicopathological factors and treatment outcome in oral cavity squamous cell carcinoma. Medicine (Baltimore) 94:e1510, 2015

21. Al-Mamgani A, van Werkhoven E, Navran A, et al: Contralateral regional recurrence after elective unilateral neck irradiation in oropharyngeal carcinoma: A literature-based critical review. Cancer Treat Rev 59:102-108, 2017

22. Alvarez Amézaga J, Barbier Herrero L, Pijoan del Barrio JI, et al: Diagnostic efficacy of sentinel node biopsy in oral squamous cell carcinoma. Cohort study and meta-analysis. Med Oral Patol Oral Cir Bucal 12:E235-E243, 2007

23. Ang KK, Trotti A, Brown BW, et al: Randomized trial addressing risk features and time factors of surgery plus radiotherapy in advanced head-and-neck cancer. Int J Radiat Oncol Biol Phys 51:571-578, 2001

24. Bernier J, Domenge C, Ozsahin M, et al: Postoperative irradiation with or without concomitant chemotherapy for locally advanced head and neck cancer. N Engl J Med 350:1945-1952, 2004

25. Bier J, Schlums D, Metelmann H, et al: A comparison of radical and conservative neck dissection. Int J Oral Maxillofac Surg 22:102-107, 1993

26. Boysen M, Lövdal O, Söberg R, et al: Elective radiotherapy of the neck in patients with squamous cell carcinoma of the head and neck. ORL J Otorhinolaryngol Relat Spec 54:103-107, 1992

27. Brennan S, Corry J, Kleid S, et al: Prospective trial to evaluate staged neck dissection or elective neck radiotherapy in patients with CT-staged T1-2 NO squamous cell carcinoma of the oral tongue. Head Neck 32:191-198, 2010

28. Broglie MA, Haile SR, Stoeckli SJ: Long-term experience in sentinel node biopsy for early oral and oropharyngeal squamous cell carcinoma. Ann Surg Oncol 18:2732-2738, 2011

29. Brown JS, Shaw RJ, Bekiroglu F, et al: Systematic review of the current evidence in the use of postoperative radiotherapy for oral squamous cell carcinoma. Br J Oral Maxillofac Surg 50:481-489, 2012

30. Carinci F, Cassano L, Farina A, et al: Unresectable primary tumor of head and neck: Does neck dissection combined with chemoradiotherapy improve survival? J Craniofac Surg 12:438-443, 2001

31. Chen AY, Vilaseca I, Hudgins PA, et al: PET-CT vs contrast-enhanced CT: What is the role for each after chemoradiation for advanced oropharyngeal cancer? Head Neck 28:487-495, 2006

32. Chung MK, Lee GJ, Choi N, et al: Comparative study of sentinel lymph node biopsy in clinically NO oral tongue squamous cell carcinoma: Long-term oncologic outcomes between validation and application phases. Oral Oncol 51:914-920, 2015

33. Civantos FJ, Zitsch RP, Schuller DE, et al: Sentinel lymph node biopsy accurately stages the regional lymph nodes for T1-T2 oral squamous cell carcinomas: Results of a prospective multi-institutional trial. J Clin Oncol 28:1395-1400, 2010

34. Cooper JS, Pajak TF, Forastiere AA, et al: Postoperative concurrent radiotherapy and chemotherapy for high-risk squamous-cell carcinoma of the head and neck. N Engl J Med 350:1937-1944, 2004

35. Cooper JS, Zhang Q, Pajak TF, et al: Long-term follow-up of the RTOG 9501/Intergroup phase III trial: Postoperative concurrent radiation therapy and chemotherapy in high-risk squamous cell carcinoma of the head and neck. Int J Radiat Oncol Biol Phys 84:1198-1205, 2012

36. Fan S, Liang FY, Chen WL, et al: Minimally invasive selective neck dissection: A prospective study of endoscopically assisted dissection via a small submandibular approach in cT(1-2_N(0) oral squamous cell carcinoma. Ann Surg Oncol 21:3876-3881, 2014

37. Fasunla AJ, Greene BH, Timmesfeld N, et al: A meta-analysis of the randomized controlled trials on elective neck dissection versus therapeutic neck dissection in oral cavity cancers with clinically node-negative neck. Oral Oncol 47:320-324, 2011

38. Gordin A, Golz A, Keidar Z, et al: The role of FDG-PET/CT imaging in head and neck malignant conditions: Impact on diagnostic accuracy and patient care. Otolaryngol Head Neck Surg 137:130-137, 2007

39. Guo CB, Feng Z, Zhang JG, et al: Supraomohyoid neck dissection and modified radical neck dissection for clinically node-negative oral squamous cell carcinoma: A prospective study of prognosis, complications and quality of life. J Craniomaxillofac Surg 42:1885-1890, 2014 
40. Kovács AF, Döbert N, Gaa J, et al: Positron emission tomography in combination with sentinel node biopsy reduces the rate of elective neck dissections in the treatment of oral and oropharyngeal cancer. J Clin Oncol 22:3973-3980, 2004

41. Laverick S, Lowe D, Brown JS, et al: The impact of neck dissection on health-related quality of life. Arch Otolaryngol Head Neck Surg 130:149-154, 2004

42. Liang L, Zhang T, Kong Q, et al: A meta-analysis on selective versus comprehensive neck dissection in oral squamous cell carcinoma patients with clinically node-positive neck. Oral Oncol 51:1076-1081, 2015

43. Liao LJ, Hsu WL, Wang CT, et al: Analysis of sentinel node biopsy combined with other diagnostic tools in staging cNO head and neck cancer: A diagnostic meta-analysis. Head Neck 38:628-634, 2016

44. Liu M, Wang SJ, Yang X, et al: Diagnostic efficacy of sentinel lymph node biopsy in early oral squamous cell carcinoma: A meta-analysis of 66 studies. PLoS One 12:e0170322, 2017

45. Mehanna H, McConkey CC, Rahman JK, et al: PET-NECK: A multicentre randomised phase III non-inferiority trial comparing a positron emission tomographycomputerised tomography-guided watch-and-wait policy with planned neck dissection in the management of locally advanced (N2/N3) nodal metastases in patients with squamous cell head and neck cancer. Health Technol Assess 21:1-122, 2017

46. Mehanna H, Wong WL, McConkey CC, et al: PET-CT surveillance versus neck dissection in advanced head and neck cancer. N Engl J Med 374:1444-1454, 2016

47. Mishra RC, Singh DN, Mishra TK: Post-operative radiotherapy in carcinoma of buccal mucosa, a prospective randomized trial. Eur J Surg Oncol 22:502-504, 1996

48. Nayak JV, Walvekar RR, Andrade RS, et al: Deferring planned neck dissection following chemoradiation for stage IV head and neck cancer: The utility of PETCT. Laryngoscope 117:2129-2134, 2007

49. Parikh S, Tedman BM, Scott B, et al: A double blind randomised trial of Ilb or not Ilb neck dissections on electromyography, clinical examination, and questionnaire-based outcomes: A feasibility study. Br J Oral Maxillofac Surg 50:394-403, 2012

50. Park JT, Roh JL, Kim JS, et al: ${ }^{18} \mathrm{~F} F D G$ PET/CT versus CT/MR imaging and the prognostic value of contralateral neck metastases in patients with head and neck squamous cell carcinoma. Radiology 279:481-491, 2016

51. Racadot S, Mercier M, Dussart S, et al: Randomized clinical trial of post-operative radiotherapy versus concomitant carboplatin and radiotherapy for head and neck cancers with lymph node involvement. Radiother Oncol 87:164-172, 2008

52. Rathod S, Livergant J, Klein J, et al: A systematic review of quality of life in head and neck cancer treated with surgery with or without adjuvant treatment. Oral Oncol 51:888-900, 2015

53. Ren ZH, Xu JL, Li B, et al: Elective versus therapeutic neck dissection in node-negative oral cancer: Evidence from five randomized controlled trials. Oral Oncol 51:976-981, 2015

54. Robbins KT, Doweck I, Samant S, et al: Effectiveness of superselective and selective neck dissection for advanced nodal metastases after chemoradiation. Arch Otolaryngol Head Neck Surg 131:965-969, 2005

55. Robertson AG, Soutar DS, Paul J, et al: Early closure of a randomized trial: Surgery and postoperative radiotherapy versus radiotherapy in the management of intra-oral tumours. Clin Oncol (R Coll Radiol) 10:155-160, 1998

56. Ryu IS, Roh JL, Kim JS, et al: Impact of ${ }^{18} \mathrm{~F}-\mathrm{FDG}$ PET/CT staging on management and prognostic stratification in head and neck squamous cell carcinoma: A prospective observational study. Eur J Cancer 63:88-96, 2016

57. Salazar-Fernandez Cl, Gallana-Alvarez S, Pereira S, et al: Sentinel lymph node biopsy in oral and oropharyngeal squamous cell carcinoma: Statistical validation and impact of micrometastasis involvement on the neck dissection decision. J Oral Maxillofac Surg 73:1403-1409, 2015

58. Su Z, Duan Z, Pan W, et al: Predicting extracapsular spread of head and neck cancers using different imaging techniques: A systematic review and metaanalysis. Int J Oral Maxillofac Surg 45:413-421, 2016

59. Terada A, Hasegawa Y, Yatabe Y, et al: Follow-up after intraoperative sentinel node biopsy of NO neck oral cancer patients. Eur Arch Otorhinolaryngol 268: 429-435, 2011

60. Terada A, Hasegawa Y, Yatabe Y, et al: Intraoperative diagnosis of cancer metastasis in sentinel lymph node of oral cancer patients. Oral Oncol 44:838-843, 2008

61. Yamauchi K, Kogashiwa Y, Nakamura T, et al: Diagnostic evaluation of sentinel lymph node biopsy in early head and neck squamous cell carcinoma: A metaanalysis. Head Neck 37:127-133, 2015

62. Al-Rajhi NM, Khafaga YM, Saleem M, et al: A study comparing different approaches in managing neck nodes in early carcinoma of the tongue. Saudi Med J 23:1343-1346, 2002

63. August M, Gianetti K: Elective neck irradiation versus observation of the clinically negative neck of patients with oral cancer. J Oral Maxillofac Surg 54: 1050-1055, 1996

64. Bittar RF, Ferraro HP, Ribas MH, et al: Predictive factors of occult neck metastasis in patients with oral squamous cell carcinoma. Rev Bras Otorrinolaringol (Engl Ed) 82:543-547, 2016

65. Böscke R, Cakir BD, Hoffmann AS, et al: Outcome after elective neck dissection and observation for the treatment of the clinically node-negative neck (cNO) in squamous cell carcinoma of the oropharynx. Eur Arch Otorhinolaryngol 271:567-574, 2014

66. Cassidy RJ, Switchenko JM, Jegadeesh N, et al: Association of lymphovascular space invasion with locoregional failure and survival in patients with nodenegative oral tongue cancers. JAMA Otolaryngol Head Neck Surg 143:382-388, 2017

67. Chatzistefanou I, Lubek J, Markou K, et al: The role of neck dissection and postoperative adjuvant radiotherapy in cNO patients with PNI-positive squamous cell carcinoma of the oral cavity. Oral Oncol 50:753-758, 2014

68. Chen TC, Wang CT, Ko JY, et al: Postoperative radiotherapy for primary early oral tongue cancer with pathologic N1 neck. Head Neck 32:555-561, 2010

69. Chen WC, Lai CH, Fang CC, et al: Identification of high-risk subgroups of patients with oral cavity cancer in need of postoperative adjuvant radiotherapy or chemo-radiotherapy. Medicine (Baltimore) 95:e3770, 2016

70. Chinn SB, Spector ME, Bellile EL, et al: Impact of perineural invasion in the pathologically NO neck in oral cavity squamous cell carcinoma. Otolaryngol Head Neck Surg 149:893-899, 2013

71. Cho AH, Shah S, Ampil F, et al: N2 disease in patients with head and neck squamous cell cancer treated with chemoradiotherapy: Is there a role for posttreatment neck dissection? Arch Otolaryngol Head Neck Surg 135:1112-1118, 2009

72. Cho KJ, Joo YH, Sun DI, et al: Management of cervical lymph node metastasis in tonsillar squamous cell carcinoma: Is it necessary to treat node-negative contralateral neck? Auris Nasus Larynx 38:501-507, 2011

73. D'Cruz AK, Siddachari RC, Walvekar RR, et al: Elective neck dissection for the management of the NO neck in early cancer of the oral tongue: Need for a randomized controlled trial. Head Neck 31:618-624, 2009 
74. Dhiwakar M, Robbins KT, Rao K, et al: Efficacy of selective neck dissection for nodal metastasis with involvement of nonlymphatic structures. Head Neck 33: 1099-1105, 2011

75. Dias FL, Kligerman J, Matos de Sá G, et al: Elective neck dissection versus observation in stage I squamous cell carcinomas of the tongue and floor of the mouth. Otolaryngol Head Neck Surg 125:23-29, 2001

76. Divi V, Chen MM, Nussenbaum B, et al: Lymph node count from neck dissection predicts mortality in head and neck cancer. J Clin Oncol 34:3892-3897, 2016

77. Divi V, Harris J, Harari PM, et al: Establishing quality indicators for neck dissection: Correlating the number of lymph nodes with oncologic outcomes (NRG Oncology RTOG 9501 and RTOG 0234). Cancer 122:3464-3471, 2016

78. Duvvuri U, Simental AA Jr, D'Angelo G, et al: Elective neck dissection and survival in patients with squamous cell carcinoma of the oral cavity and oropharynx. Laryngoscope 114:2228-2234, 2004

79. Dziegielewski PT, O'Connell DA, Szudek J, et al: Neck metastases in oropharyngeal cancer: Necessity and extent of bilateral treatment. Head Neck 35: 1461-1467, 2013

80. Feng Z, Li JN, Li CZ, et al: Elective neck dissection versus observation in the management of early tongue carcinoma with clinically node-negative neck: A retrospective study of 229 cases. J Craniomaxillofac Surg 42:806-810, 2014

81. Ganly I, Goldstein D, Carlson DL, et al: Long-term regional control and survival in patients with "low-risk," early stage oral tongue cancer managed by partial glossectomy and neck dissection without postoperative radiation: The importance of tumor thickness. Cancer 119:1168-1176, 2013

82. Hernando J, Villarreal P, Alvarez-Marcos F, et al: Comparison of related complications: Sentinel node biopsy versus elective neck dissection. Int J Oral Maxillofac Surg 43:1307-1312, 2014

83. Hicks WL Jr, Loree TR, Garcia RI, et al: Squamous cell carcinoma of the floor of mouth: A 20-year review. Head Neck 19:400-405, 1997

84. Hitchcock KE, Amdur RJ, Morris CG, et al: Retromolar trigone squamous cell carcinoma treated with radiotherapy alone or combined with surgery: A 10 -year update. Am J Otolaryngol 36:140-145, 2015

85. Iyer NG, Clark JR, Singham S, et al: Role of pretreatment 18FDG-PET/CT in surgical decision-making for head and neck cancers. Head Neck 32:1202-1208, 2010

86. Joo YH, Yoo leR, Cho KJ, et al: Relationship between extracapsular spread and FDG PET/CT in oropharyngeal squamous cell carcinoma. Acta Otolaryngol 133: 1073-1079, 2013

87. Kelner N, Vartanian JG, Pinto CA, et al: Does elective neck dissection in T1/T2 carcinoma of the oral tongue and floor of the mouth influence recurrence and survival rates? Br J Oral Maxillofac Surg 52:590-597, 2014

88. Keski-Säntti H, Atula T, Törnwall J, et al: Elective neck treatment versus observation in patients with T1/T2 NO squamous cell carcinoma of oral tongue. Oral Oncol 42:96-101, 2006

89. Khodayari B, Daly ME, Bobinski M, et al: Observation versus neck dissection for positron-emission tomography-negative lymphadenopathy after chemoradiotherapy. Laryngoscope 124:902-906, 2014

90. Lavaf A, Genden EM, Cesaretti JA, et al: Adjuvant radiotherapy improves overall survival for patients with lymph node-positive head and neck squamous cell carcinoma. Cancer 112:535-543, 2008

91. Liao CT, Lin CY, Fan KH, et al: Identification of a high-risk subgroup of patients with resected pT3 oral cavity cancer in need of postoperative adjuvant therapy. Ann Surg Oncol 18:2569-2578, 2011

92. Lim YC, Koo BS, Lee JS, et al: Distributions of cervical lymph node metastases in oropharyngeal carcinoma: Therapeutic implications for the NO neck. Laryngoscope 116:1148-1152, 2006

93. Malone JP, Gerberi MA, Vasireddy S, et al: Early prediction of response to chemoradiotherapy for head and neck cancer: Reliability of restaging with combined positron emission tomography and computed tomography. Arch Otolaryngol Head Neck Surg 135:1119-1125, 2009

94. Montes DM, Carlson ER, Fernandes R, et al: Oral maxillary squamous carcinoma: An indication for neck dissection in the clinically negative neck. Head Neck 33:1581-1585, 2011

95. Da Mosto MC, Lupato V, Romeo S, et al: Is neck dissection necessary after induction plus concurrent chemoradiotherapy in complete responder head and neck cancer patients with pretherapy advanced nodal disease? Ann Surg Oncol 20:250-256, 2013

96. Najim M, Cross S, Gebski V, et al: Early-stage squamous cell carcinoma of the lip: The Australian experience and the benefits of radiotherapy in improving outcome in high-risk patients after resection. Head Neck 35:1426-1430, 2013

97. Orabona GD, Bonavolontà P, Maglitto F, et al: Neck dissection versus "watchful-waiting" in early squamous cell carcinoma of the tongue our experience on 127 cases. Surg Oncol 25:401-404, 2016

98. Patel RS, Clark JR, Gao K, et al: Effectiveness of selective neck dissection in the treatment of the clinically positive neck. Head Neck 30:1231-1236, 2008

99. Prabhu RS, Magliocca KR, Hanasoge S, et al: Accuracy of computed tomography for predicting pathologic nodal extracapsular extension in patients with head-and-neck cancer undergoing initial surgical resection. Int J Radiat Oncol Biol Phys 88:122-129, 2014

100. Roberts TJ, Colevas AD, Hara W, et al: Number of positive nodes is superior to the lymph node ratio and American Joint Committee on Cancer $\mathrm{N}$ staging for the prognosis of surgically treated head and neck squamous cell carcinomas. Cancer 122:1388-1397, 2016

101. Sanguineti G, Pai S, Agbahiwe H, et al: HPV-related oropharyngeal carcinoma with overt level II and/or III metastases at presentation: The risk of subclinical disease in ipsilateral levels IB, IV and V. Acta Oncol 53:662-668, 2014

102. Schoppy DW, Rhoads KF, Ma Y, et al: Measuring institutional quality in head and neck surgery using hospital-level data: Negative margin rates and neck dissection yield. JAMA Otolaryngol Head Neck Surg 143:1111-1116, 2017

103. Spiotto MT, Jefferson G, Wenig B, et al: Differences in survival with surgery and postoperative radiotherapy compared with definitive chemoradiotherapy for oral cavity cancer: A National Cancer Database analysis. JAMA Otolaryngol Head Neck Surg 143:691-699, 2017

104. Wan XC, Egloff AM, Johnson J: Histological assessment of cervical lymph node identifies patients with head and neck squamous cell carcinoma (HNSCC): Who would benefit from chemoradiation after surgery? Laryngoscope 122:2712-2722, 2012

105. Zenga J, Jackson RS, Graboyes EM, et al: Oncologic outcomes of selective neck dissection in HPV-related oropharyngeal squamous cell carcinoma. Laryngoscope 127:623-630, 2017

106. Pantvaidya GH, Pal P, Vaidya AD, et al: Prospective study of 583 neck dissections in oral cancers: Implications for clinical practice. Head Neck 36:1503-1507, 2014

107. Crean SJ, Hoffman A, Potts J, et al: Reduction of occult metastatic disease by extension of the supraomohyoid neck dissection to include level IV. Head Neck 25:758-762, 2003

108. Dias FL, Lima RA, Kligerman J, et al: Relevance of skip metastases for squamous cell carcinoma of the oral tongue and the floor of the mouth. Otolaryngol Head Neck Surg 134:460-465, 2006 
109. Elsheikh MN, Mahfouz ME, Elsheikh E: Level Ilb lymph nodes metastasis in elective supraomohyoid neck dissection for oral cavity squamous cell carcinoma: A molecular-based study. Laryngoscope 115:1636-1640, 2005

110. Singh B, Nair S, Nair D, et al: Ipsilateral neck nodal status as predictor of contralateral nodal metastasis in carcinoma of tongue crossing the midline. Head Neck 35:649-652, 2013

111. Liao CT, Lin CY, Fan KH, et al: Identification of a high-risk group among patients with oral cavity squamous cell carcinoma and pT1-2NO disease. Int J Radiat Oncol Biol Phys 82:284-290, 2012

112. Ambrosch P, Kron M, Pradier $\mathrm{O}$, et al: Efficacy of selective neck dissection: A review of 503 cases of elective and therapeutic treatment of the neck in squamous cell carcinoma of the upper aerodigestive tract. Otolaryngol Head Neck Surg 124:180-187, 2001

113. Byers RM, Clayman GL, McGill D, et al: Selective neck dissections for squamous carcinoma of the upper aerodigestive tract: Patterns of regional failure. Head Neck 21:499-505, 1999

114. Hosal AS, Carrau RL, Johnson JT, et al: Selective neck dissection in the management of the clinically node-negative neck. Laryngoscope 110:2037-2040, 2000

115. Schiff BA, Roberts DB, El-Naggar A, et al: Selective vs modified radical neck dissection and postoperative radiotherapy vs observation in the treatment of squamous cell carcinoma of the oral tongue. Arch Otolaryngol Head Neck Surg 131:874-878, 2005

116. Jäckel MC, Ambrosch P, Christiansen H, et al: Value of postoperative radiotherapy in patients with pathologic N1 neck disease. Head Neck 30:875-882, 2008

117. Liao CT, Hsueh C, Lee LY, et al: Neck dissection field and lymph node density predict prognosis in patients with oral cavity cancer and pathological node metastases treated with adjuvant therapy. Oral Oncol 48:329-336, 2012

118. Foster CC, Melotek JM, Brisson RJ, et al: Definitive chemoradiation for locally-advanced oral cavity cancer: A 20-year experience. Oral Oncol 80:16-22, 2018

119. Scher ED, Romesser PB, Chen C, et al: Definitive chemoradiation for primary oral cavity carcinoma: A single institution experience. Oral Oncol 51:709-715, 2015

120. Murthy V, Agarwal JP, Laskar SG, et al: Analysis of prognostic factors in 1180 patients with oral cavity primary cancer treated with definitive or adjuvant radiotherapy. J Cancer Res Ther 6:282-289, 2010

121. Gleysteen J, Troob S, Light T, et al: The impact of prophylactic external carotid artery ligation on postoperative bleeding after transoral robotic surgery (TORS) for oropharyngeal squamous cell carcinoma. Oral Oncol 70:1-6, 2017

122. Kubik M, Mandal R, Albergotti W, et al: Effect of transcervical arterial ligation on the severity of postoperative hemorrhage after transoral robotic surgery. Head Neck 39:1510-1515, 2017

123. Bernier J, Cooper JS, Pajak TF, et al: Defining risk levels in locally advanced head and neck cancers: A comparative analysis of concurrent postoperative radiation plus chemotherapy trials of the EORTC (\#22931) and RTOG (\# 9501). Head Neck 27:843-850, 2005

124. Lewis JS Jr, Carpenter DH, Thorstad WL, et al: Extracapsular extension is a poor predictor of disease recurrence in surgically treated oropharyngeal squamous cell carcinoma. Mod Pathol 24:1413-1420, 2011

125. Sinha P, Lewis JS Jr, Piccirillo JF, et al: Extracapsular spread and adjuvant therapy in human papillomavirus-related, p16-positive oropharyngeal carcinoma. Cancer 118:3519-3530, 2012

126. An Y, Park HS, Kelly JR, et al: The prognostic value of extranodal extension in human papillomavirus-associated oropharyngeal squamous cell carcinoma. Cancer 123:2762-2772, 2017

127. Adelstein DJ, Li Y, Adams GL, et al: An intergroup phase III comparison of standard radiation therapy and two schedules of concurrent chemoradiotherapy in patients with unresectable squamous cell head and neck cancer. J Clin Oncol 21:92-98, 2003

128. Greven KM, Williams DW III, McGuirt WF Sr, et al: Serial positron emission tomography scans following radiation therapy of patients with head and neck cancer. Head Neck 23:942-946, 2001

129. Ryan WR, Fee WE Jr, Le QT, et al: Positron-emission tomography for surveillance of head and neck cancer. Laryngoscope 115:645-650, 2005

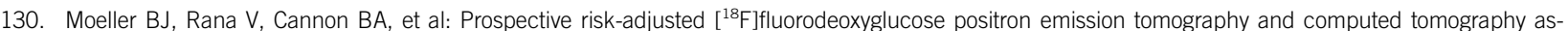
sessment of radiation response in head and neck cancer. J Clin Oncol 27:2509-2515, 2009

131. Brazilian Head and Neck Cancer Study Group: Results of a prospective trial on elective modified radical classical versus supraomohyoid neck dissection in the management of oral squamous carcinoma. Am J Surg 176:422-427, 1998

132. Noronha V, Joshi A, Patil VM, et al: Once-a-week versus once-every-3-weeks cisplatin chemoradiation for locally advanced head and neck cancer: A phase III randomized noninferiority trial. J Clin Oncol 36:1064-1072, 2018

133. Yao M, Smith RB, Hoffman HT, et al: Clinical significance of postradiotherapy [ $\left.{ }^{18} \mathrm{~F}\right]-$ fluorodeoxyglucose positron emission tomography imaging in management of head-and-neck cancer: A long-term outcome report. Int J Radiat Oncol Biol Phys 74:9-14, 2009

134. Porceddu SV, Jarmolowski E, Hicks RJ, et al: Utility of positron emission tomography for the detection of disease in residual neck nodes after (chemo) radiotherapy in head and neck cancer. Head Neck 27:175-181, 2005

135. Ho AS, Kim S, Tighiouart M, et al: Metastatic lymph node burden and survival in oral cavity cancer. J Clin Oncol 35:3601-3609, 2017

136. Bachaud JM, Cohen-Jonathan E, Alzieu C, et al: Combined postoperative radiotherapy and weekly cisplatin infusion for locally advanced head and neck carcinoma: Final report of a randomized trial. Int J Radiat Oncol Biol Phys 36:999-1004, 1996

137. Vergeer MR, Doornaert PA, de Bree R, et al: Postoperative elective nodal irradiation for squamous cell carcinoma of the head and neck: Outcome and prognostic factors for regional recurrence. Ann Oncol 22:2489-2494, 2011

138. Kligerman J, Lima RA, Soares JR, et al: Supraomohyoid neck dissection in the treatment of T1/T2 squamous cell carcinoma of oral cavity. Am J Surg 168 : 391-394, 1994

139. Yuen AP, Ho CM, Chow TL, et al: Prospective randomized study of selective neck dissection versus observation for NO neck of early tongue carcinoma. Head Neck 31:765-772, 2009

140. Bessell A, Glenny AM, Furness S, et al: Interventions for the treatment of oral and oropharyngeal cancers: Surgical treatment. Cochrane Database Syst Rev 2011:CD006205, 2011

141. Corry J, Peters L, Fisher R, et al: N2-N3 neck nodal control without planned neck dissection for clinical/radiologic complete responders-results of Trans Tasman Radiation Oncology Group Study 98.02. Head Neck 30:737-742, 2008

142. Porceddu SV, Pryor DI, Burmeister E, et al: Results of a prospective study of positron emission tomography-directed management of residual nodal abnormalities in node-positive head and neck cancer after definitive radiotherapy with or without systemic therapy. Head Neck 33:1675-1682, 2011

143. Ebrahimi A, Clark JR, Amit M, et al: Minimum nodal yield in oral squamous cell carcinoma: Defining the standard of care in a multicenter international pooled validation study. Ann Surg Oncol 21:3049-3055, 2014

144. American Joint Committee on Cancer: Cancer Staging Manual (ed 8). New York, NY, Springer International Publishing, 2017

145. Fakih AR, Rao RS, Patel AR: Prophylactic neck dissection in squamous cell carcinoma of oral tongue: A prospective randomized study. Semin Surg Oncol 5 : 327-330, 1989 
146. Vandenbrouck C, Sancho-Garnier H, Chassagne D, et al: Elective versus therapeutic radical neck dissection in epidermoid carcinoma of the oral cavity: Results of a randomized clinical trial. Cancer 46:386-390, 1980

147. de Bree R, van den Brekel MWM: Elective neck dissection versus observation in the clinically node negative neck in early oral cancer: Do we have the answer yet? Oral Oncol 51:963-965, 2015

148. Schilling C, Stoeckli SJ, Haerle SK, et al: Sentinel European Node Trial (SENT): 3-Year results of sentinel node biopsy in oral cancer. Eur J Cancer 51: 2777-2784, 2015

149. van den Brekel MW, Reitsma LC, Quak JJ, et al: Sonographically guided aspiration cytology of neck nodes for selection of treatment and follow-up in patients with NO head and neck cancer. AJNR Am J Neuroradiol 20:1727-1731, 1999

150. Flach GB, Tenhagen M, de Bree R, et al: Outcome of patients with early stage oral cancer managed by an observation strategy towards the NO neck using ultrasound guided fine needle aspiration cytology: No survival difference as compared to elective neck dissection. Oral Oncol 49:157-164, 2013

151. Ebrahimi A, Zhang WJ, Gao K, et al: Nodal yield and survival in oral squamous cancer: Defining the standard of care. Cancer 117:2917-2925, 2011

152. Marres CC, de Ridder M, Hegger I, et al: The influence of nodal yield in neck dissections on lymph node ratio in head and neck cancer. Oral Oncol 50:59-64, 2014

153. Langendijk JA, Slotman BJ, van der Waal I, et al: Risk-group definition by recursive partitioning analysis of patients with squamous cell head and neck carcinoma treated with surgery and postoperative radiotherapy. Cancer 104:1408-1417, 2005

154. Cooper JS, Pajak TF, Forastiere A, et al: Precisely defining high-risk operable head and neck tumors based on RTOG \#85-03 and \#88-24: Targets for postoperative radiochemotherapy? Head Neck 20:588-594, 1998

155. Quon H, Vapiwala N, Forastiere A, et al: Radiation therapy for oropharyngeal squamous cell carcinoma: American Society of Clinical Oncology endorsement of the American Society for Radiation Oncology evidence-based clinical practice guideline. J Clin Oncol 35:4078-4090, 2017

156. Sher DJ, Adelstein DJ, Bajaj GK, et al: Radiation therapy for oropharyngeal squamous cell carcinoma: Executive summary of an ASTRO evidence-based clinical practice guideline. Pract Radiat Oncol 7:246-253, 2017

157. Chaturvedi AK, Engels EA, Pfeiffer RM, et al: Human papillomavirus and rising oropharyngeal cancer incidence in the United States. J Clin Oncol 29: 4294-4301, 2011

158. Holsinger FC, Ferris RL: Transoral endoscopic head and neck surgery and its role within the multidisciplinary treatment paradigm of oropharynx cancer: Robotics, lasers, and clinical trials. J Clin Oncol 33:3285-3292, 2015

159. Cracchiolo JR, Baxi SS, Morris LG, et al: Increase in primary surgical treatment of T1 and T2 oropharyngeal squamous cell carcinoma and rates of adverse pathologic features: National Cancer Data Base. Cancer 122:1523-1532, 2016

160. Robbins KT, Shaha AR, Medina JE, et al: Consensus statement on the classification and terminology of neck dissection. Arch Otolaryngol Head Neck Surg 134:536-538, 2008

161. Rassekh CH, O'Malley BW Jr, Bewley AF, et al: Feasibility and relevance of level I substation node counts in oropharyngeal carcinoma. Head Neck 38 : 1194-1200, 2016

162. Zhu GA, Lira R, Colevas AD: Discordance in routine second opinion pathology review of head and neck oncology specimens: A single-center five year retrospective review. Oral Oncol 53:36-41, 2016

163. Wong SJ, Li L, Hess LM, et al: Utilization and outcomes of low dose versus high dose cisplatin in head and neck cancer patients receiving concurrent radiation. J Clin Oncol 33, 2015 (abstr 6019)

164. Vermorken JB, Mesia R, Rivera F, et al: Platinum-based chemotherapy plus cetuximab in head and neck cancer. N Engl J Med 359:1116-1127, 2008

165. Ferris RL, Blumenschein G Jr, Fayette J, et al: Nivolumab for recurrent squamous-cell carcinoma of the head and neck. N Engl J Med 375:1856-1867, 2016

166. Gilligan T, Coyle N, Frankel RM, et al: Patient-clinician communication: American Society of Clinical Oncology consensus guideline. J Clin Oncol 35: 3618-3632, 2017

167. National Cancer Institute: SEER cancer statistics review, 1975-2013. http://seer.cancer.gov/csr/1975_2013/

168. American Cancer Society: Cancer facts and figures for African Americans 2016-2018. http://www.cancer.org/acs/groups/content/@editorial/documents/ document/acspc-047403.pdf

169. US Centers for Disease Control and Prevention: United States cancer statistics: 1999-2012 Incidence and mortality Web-based report. http://www.cdc.gov/ uscS

170. Jones K, Siegel B, Mead H, et al: Racial and Ethnic Disparities in U.S. Health Care: A Chartbook. New York, NY, The Commonwealth Fund, 2008

171. Schnipper LE, Davidson NE, Wollins DS, et al: Updating the American Society of Clinical Oncology value framework: Revisions and reflections in response to comments received. J Clin Oncol 34:2925-2934, 2016

172. Schnipper LE, Davidson NE, Wollins DS, et al: American Society of Clinical Oncology statement: A conceptual framework to assess the value of cancer treatment options. J Clin Oncol 33:2563-2577, 2015

173. Streeter SB, Schwartzberg L, Husain N, et al: Patient and plan characteristics affecting abandonment of oral oncolytic prescriptions. J Oncol Pract 7:46s-51s, 2011 (suppl)

174. Dusetzina SB, Winn AN, Abel GA, et al: Cost sharing and adherence to tyrosine kinase inhibitors for patients with chronic myeloid leukemia. J Clin Oncol 32 : 306-311, 2014

175. Meropol NJ, Schrag D, Smith TJ, et al: American Society of Clinical Oncology guidance statement: The cost of cancer care. J Clin Oncol 27:3868-3874, 2009

176. Ferrell BR, Temel JS, Temin S, et al: Integration of palliative care into standard oncology care: American Society of Clinical Oncology clinical practice guideline update. J Clin Oncol 35:96-112, 2017

177. Fakhry C, Lacchetti C, Rooper LM, et al: Human papillomavirus testing in head and neck carcinomas: ASCO clinical practice guideline endorsement of the College of American Pathologists guideline. J Clin Oncol 36:3152-3161, 2018

178. Forastiere AA, Ismaila N, Lewin JS, et al: Use of larynx-preservation strategies in the treatment of laryngeal cancer: American Society of Clinical Oncology clinical practice guideline update. J Clin Oncol 36:1143-1169, 2018

179. Nekhlyudov L, Lacchetti C, Davis NB, et al: Head and neck cancer survivorship care guideline: American Society of Clinical Oncology clinical practice guideline endorsement of the American Cancer Society guideline. J Clin Oncol 35:1606-1621, 2017 


\section{Management of the Neck in Squamous Cell Carcinoma of the Oral Cavity and Oropharynx: ASCO Clinical Practice Guideline}

The following represents disclosure information provided by authors of this manuscript. All relationships are considered compensated. Relationships are self-held unless noted. I = Immediate Family Member, Inst = My Institution. Relationships may not relate to the subject matter of this manuscript. For more information about ASCO's conflict of interest policy, please refer to www.asco.org/rwc or ascopubs.org/jco/site/ifc.

Shlomo A. Koyfman

Research Funding: Merck Sharp \& Dohme

Other Relationship: Varian Medical Systems, UpToDate

Doug Crook

Stock and Other Ownership Interests: Eli Lilly

Cristina P. Rodriguez

Research Funding: Merck (Inst), AstraZeneca (Inst), MedImmune (Inst), BristolMyers Squibb (Inst), Ignyta (Inst)

Damian Silbermins

Stock and Other Ownership Interests: MEI Pharma, Celldex, Sangamo

Therapeutics, Achaogen

Honoraria: M3, Zoomrx

Speakers' Bureau: Celgene, Novartis, Bristol-Myers Squibb

\section{Jared Weiss}

Stock and Other Ownership Interests: Nektar

Honoraria: Pfizer

Consulting or Advisory Role: AstraZeneca, EMD Serono, Genentech, Inivata, BioMarck Pharmaceuticals, Celgene, G1 Therapeutics

Research Funding: Astellas Pharma (Inst), Celgene (Inst), Pfizer (Inst), Novartis (Inst), Merck (Inst), AstraZeneca (Inst), Medlmmune (Inst)

Sue S. Yom

Consulting or Advisory Role: BioMimetix

Research Funding: Genentech (Inst), Merck (Inst), Bristol-Myers Squibb (Inst) Patents, Royalties, Other Intellectual Property: UpToDate, Springer

F. Christopher Holsinger

Patents, Royalties, Other Intellectual Property: Surgical Vision Technologies

No other potential conflicts of interest were reported. 


\section{APPENDIX}

TABLE A1. Management of the Neck in Squamous Cell Carcinoma of the Oral Cavity and Oropharynx: ASCO Clinical Practice Guideline Expert Panel Membership

Name

Affiliation/Institution

\begin{tabular}{lll}
\hline F. Christopher Holsinger, MD (co-chair) & Stanford University, Palo Alto, CA & Surgical oncology \\
\hline Shlomo A. Koyfman, MD (co-chair) & Cleveland Clinic, Cleveland, OH & Radiation oncology \\
\hline Sue S. Yom, MD & University of California, San Francisco, San Francisco, CA & Radiation oncology \\
\hline Erich M. Sturgis, MD & MD Anderson Cancer Center, Houston, TX & Surgical oncology \\
\hline Anil D'Cruz, MD & $\begin{array}{l}\text { Department of Medical Oncology, Tata Memorial Centre, } \\
\text { Mumbai, India }\end{array}$ & Surgical oncology \\
\hline Terance Tsue, MD (AHNS representative) & University of Kansas Cancer Center, Kansas City, KS & Surgical oncology \\
\hline David J. Sher, MD (ASTRO representative) & University of Texas Southwestern, Dallas, TX & Radiation oncology \\
\hline Cristina P. Rodriguez, MD & Seattle Cancer Care Alliance, Seattle, WA & Medical oncology \\
\hline Jared Weiss, MD & Lineberger Comprehensive Cancer Center at the University & Medical oncology \\
& of North Carolina, Chapel Hill, NC & PGIN representative \\
\hline Damian Silbermins, MD & Huntington Internal Medicine Group, Huntington, WV & Patient representative \\
\hline Doug Crook & Indianapolis, IN & Staff/health research methodologist
\end{tabular}

Abbreviations: AHNS, American Head and Neck Society; ASTRO, American Society for Radiation Oncology; PGIN, Practice Guideline Implementation Network. 